\title{
Is the United States a Counterexample to the Secularization Thesis? ${ }^{1}$
}

\author{
David Voas \\ University College London \\ Mark Chaves \\ Duke University
}

\begin{abstract}
Virtually every discussion of secularization asserts that high levels of religiosity in the United States make it a decisive counterexample to the claim that modern societies are prone to secularization. Focusing on trends rather than levels, the authors maintain that, for two straightforward empirical reasons, the United States should no longer be considered a counterexample. First, it has recently become clear that American religiosity has been declining for decades. Second, this decline has been produced by the generational patterns underlying religious decline elsewhere in the West: each successive cohort is less religious than the preceding one. America is not an exception. These findings change the theoretical import of the United States for debates about secularization.
\end{abstract}

\section{INTRODUCTION}

The religiosity of the United States has impressed observers at least since the time of Alexis de Tocqueville, and to this day American levels of religious involvement remain strikingly high compared to those in virtually all

\footnotetext{
${ }^{1}$ The research was supported by funding from the U.K. Economic and Social Research Council. The work was begun with the late Alasdair Crockett and continued with the assistance of Sarah King-Hele. The authors thank David Eagle, Brad Fulton, David Hollinger, Jörg Stolz, and Ed Tiryakian for helpful comments on an earlier version. Direct correspondence to David Voas, Department of Social Science, UCL IOE, University College London, London WC1H 0AL, United Kingdom. E-mail: d.voas@ucl.ac.uk
}

(C) 2016 by The University of Chicago. All rights reserved.

0002-9602/2016/12105-0005\$10.00 
highly developed countries. Many features of this well-known phenomenon could be explored, but we focus on the enormous weight it carries in debates about the secularization thesis - the idea that modernization tends to undermine religious belief and activity. However one defines "modernization," critics of the secularization thesis commonly treat the United States - an indisputably modern yet highly religious country — as a decisive counterexample to that thesis. The state of American religion is not the only evidence that critics marshal against the secularization thesis, but the religious situation in the United States often, perhaps always, plays a key role in the criticism.

Berger, Davie, and Fokas, for example, do not mince words when they write that the "comparison [between European and American religion] is crucial, not only because it helps to shoot out of the water the aforementioned secularization theory" (2008, p. 21). Later in the same book, they similarly write: "There have been many reasons for the demise of secularization theory . . . but the America-Europe comparison is a big nail in the coffin of the theory" (p. 141). Whether or not they are critics of the secularization thesis, reviewers of the secularization literature uniformly recognize the crucial importance of the American case. De Graaf, for example, notes how "the relatively high levels of religious participation in the United States cast doubt on the secularization thesis" (2013, p. 321). The author of the "American Exceptionalism?" chapter in the most recent Blackwell Companion to the Sociology of Religion puts it this way: "The decline of secularization theory ... has resulted in considerable part from coming to terms with the fact that the United States has been more given to religious observance than its Western European cousins" (Torpey 2010, p. 155). And in their Annual Review of Sociology article on the subject, Gorski and Altinordu (2008, p. 57) observed that "defining secularization [as a decline in individual belief and practice] allows [secularization critics] to argue that the United States is a fatal anomaly for secularization because the United States is indisputably modern (urbanized, democratized, industrialized, rationalized, etc.) but not secular in their terms."

Perhaps the clearest representation of this "United States as secularization counterexample" claim is a graph included in the first chapter of Wald and Calhoun-Brown's widely used textbook, Religion and Politics in the United States (2011, p. 9). The graph shows the strong linear negative relationship across 47 countries between economic development (measured as gross national income per capita) and the proportion of people saying that religion is "very important" in their lives. But the United States is an outlier, lying well off the regression line. The graph's theoretical import is clear: "American religion, like Mark Twain, has obstinately refused to comply with reports of its demise. . . The naïve model of secularization cannot withstand the facts" (p. 8). 
Critics of the secularization thesis sometimes also assert that American levels of religiosity are not just high but have been stable for decades. Greeley's elegant and influential 1989 summary of American religious trends, for example, concluded by observing that, although a few minor survey items show change over time, "most of the other social indicators discussed in the previous chapters best fit - sometimes with minor adjustments - the stability model." He draws the usual conclusion: "If [these indicators of religiosity] have not changed, is there not reason to assert that there is a certain longterm stability in American religious behavior whatever important changes might also be occurring? Is there not even more reason to assert that the secularization model . . . is unsupported by the available social indicators?" (Greeley 1989, pp. 115-16). ${ }^{2}$

Critics of the secularization thesis sometimes accept some evidence of decline in American religion but then discount the theoretical significance of that decline. Berger et al., for example, acknowledge some decline but dismiss its importance: "In the United States, [unbelief] is also growing, but from an infinitesimally small base" (2008, p. 57). Martin discounts religious decline in the United States in a different way: "The USA as a whole has been known for the remarkably stable character of its religion since indices peaked in the mid-twentieth century, and that has remained true until recently" (2011, p. 88). And Putnam and Campbell discount the significance of religious decline in yet another way: "If we are witnessing such a [secularization] process in the United States, at this rate it will take a couple of centuries to reduce American religious observance to the current European levels. .. . Thus, while recognizing the slow generational decline in American religiosity over the last half century, we are skeptical about bold assertions of secularization in America" (2010, p. 76). In short, when looking at the United States, secularization critics either deny religious decline or, when acknowledging some decline, discount its significance by emphasizing the still high levels of American religiosity, the recent start of decline, or the slowness of decline. The result is to preserve the United States' standing as a decisive counterexample to the secularization thesis.

Defenders of the secularization thesis similarly recognize the theoretical import of the United States. For them, embarrassingly strong American religion presents a case with which they must grapple, a puzzle they must somehow solve to sustain the secularization thesis. The most common solution has been to claim that American religiosity is somehow not as religious as it appears to be. Perhaps the most famous version of this response is Luckmann's 1967 invocation of internal secularization: "The distribution of church religion in America, nevertheless, does not represent a reversal

${ }^{2}$ See Berger et al. (2008, p. 21) and Wald and Calhoun-Brown (2011, pp. 13-14) for similar claims. 
of the trend toward 'secularization'-that is, a resurgence of traditional church religion. It is rather the result of a radical inner change in American church religion. ... We are led to the conclusion that traditional church religion was pushed to the periphery of 'modern' life in Europe while it became more 'modern' in America by undergoing a process of internal secularization" (Luckman 1967, pp. 36-37). This same kind of response was offered more recently by Steve Bruce, one of the most eloquent and staunch defenders of the secularization thesis. Approvingly citing Bryan Wilson's 1966 claim that "while Europeans secularized by abandoning the churches, Americans secularized their churches," Bruce says: "Wilson's belief that the enduring popularity of churchgoing in the USA may well reflect important changes in the substance of American religion now seems prescient. . . In addition to the evidence of church decline, we need to appreciate the extent to which the content of American Christianity has been secularized" (2011, pp. 160, 165). The now well-established fact that Americans overreport their religious service attendance, and by margins considerably greater than people in other modern countries, is also often used by defenders of the secularization thesis as evidence that American religiosity is not as strong as it appears at first glance. ${ }^{3}$

In this article, we develop the claim that the United States is not a counterexample to the secularization thesis, but not because of internal secularization. Rather, we argue that the United States should not be considered a counterexample for two straightforward empirical reasons. First, American religiosity has in fact been declining for decades, and second, that decline has been produced by the same generational patterns that lie behind religious decline elsewhere in the West: each successive cohort is less religious than the preceding one. Taken together, these two facts mean that recent trends in religiosity are remarkably similar throughout the Western world, including the United States. The common story is decline driven by cohort replacement. The United States is not an exception. And since our claim is that American religiosity should no longer be considered a counterexample even when its religiosity levels are taken at face value, we sidestep debates about whether American religiosity is truly religious. If the United States is not a secularization counterexample even if American religiosity indicates real religious commitment, then a fortiori it is not a counterexample if American religiosity is substantially overreported, if it indicates sociability more than religious belief, or if American religion is in some sense internally secularized.

\footnotetext{
${ }^{3}$ Substantial American overreporting was first established by Hadaway, Marler, and Chaves (1993); subsequent studies have confirmed it. See Brenner (2011) for international comparisons. Some writers have recently asserted that Europeans underreport their religious service attendance, but we know of no evidence documenting underreporting in any European country.
} 
We are not the first to notice the signs of American religious decline. ${ }^{4}$ However, when it is noticed at all, this decline has been minimized and discounted by secularization critics, and even advocates of the secularization thesis have pulled their punches on this point. ${ }^{5}$ We establish the decline of American religiosity more firmly than earlier scholars were able to do. Previous analysts have missed this decline, or have understated it, because the decline is slow, and only recently have we accumulated enough data over a long enough period to see it clearly. Some scholars have begun to notice these signs of erosion in religiosity, but few have grasped how strong the evidence for decades-long decline truly is, and hence the significance of that decline is discounted even by those who notice it.

Similarly, we are not the first to examine cohort differences in American religiosity. On the contrary, the analysis of such differences has a long history, characterized by mixed results. The presence or absence of generational decline in American church attendance has been particularly contentious. Sasaki and Suzuki (1987) examined attendance from 1952 to 1982 and found decline among post-1927 birth cohorts. In a paper published just three months later, Hout and Greeley (1987) argued that church attendance was stable from 1940 to 1984, with the exception of a drop among all Catholics between 1968 and 1975. Chaves (1989, 1991) found evidence of both secularization (cohort-based decline) and revival (period-based increases among Protestants). Hout and Greeley (1990) and Firebaugh and Harley (1991) contested those conclusions, arguing against the hypothesis of generational declines in religiosity and in favor of life-course increases. Ploch and Hastings (1994) came down on the side of age rather than cohort effects, while Miller and Nakamura (1996) supported the idea of generational change, although they saw it as a one-time shift associated with the 1960s rather than a gradual and continuing decline. Presser and Chaves (2007) also suggested that change may be discontinuous, on the basis of an absence of any overall trend in church attendance between 1990 and 2006. Schwadel $(2010 a)$ asserted that frequency of attendance was shaped by strong positive age effects, modest period decline in the 1990s, and no substantial cohort differences. Using a different method the following year, he concluded that "regular religious service attendance declines moderately

\footnotetext{
${ }^{4}$ The basic patterns have been described in Putnam and Campbell (2010) and in Chaves (2011). See Grant (2008) for a creative aggregate measure of religiosity that also shows decline in recent decades.

${ }^{5}$ Norris and Inglehart, e.g., say that the evidence about U.S. religiosity "remains somewhat ambiguous" because "religious participation may have eroded" and "secular tendencies may have strengthened" (Norris and Inglehart 2004, pp. 89, 94, 95; emphasis added). Similarly, in building his case for why the United States is not a secularization counterexample, Bruce (2011) relies more on American overreporting of church attendance and the ways in which American religion has internally secularized than on evidence of religious decline.
} 
from the early 1970 s to 2006 , and this change is predominantly due to differences across cohorts" (Schwadel 2011, p. 190). Age-period-cohort studies of affiliation, belief, and other indicators of religious commitment have produced similarly mixed results.

The inconsistent findings characterizing this literature have arisen partly because of the analytical difficulties in studying cohort differences and partly because it is difficult in any case to identify the components of change with data from only a couple of decades. As with the aggregate decline in religiosity, the picture has become clearer as time has passed and more data have become available. Using data that now span four decades, analyzing these data sets with straightforward methods, studying several aspects of religiosity, and placing the American cohort patterns in comparative perspective, we establish just how strong the U.S. cohort differences in religious affiliation, belief, and behavior really are and how similar they are to generation gaps observed throughout the modern world. Our results support previous research that has found strong cohort differences in American religiosity, but our primary aim is to emphasize the significance of this fact for the claim that the United States is a counterexample to the secularization thesis.

A terminological note: we will not review the secularization literature as a whole, nor will we provide yet another overview of the many thorny conceptual and empirical issues raised in debates about secularization. Excellent reviews are available elsewhere. ${ }^{6}$ Relatedly, we will not discuss the best ways to conceptualize "modernization" or "secularization." We do not engage in those debates because the United States is treated as a counterexample to the secularization thesis however "modernization" and "secularization" are defined. For our purposes, it is enough to say that modernization refers to the mix of industrialization, democratization, urbanization, rationalization, cultural diversity, expanded education, and increased prosperity that characterizes contemporary Western societies, including the United States, and that secularization refers to the decline of traditional religious belief and practice among individuals (Lipset 1959; Bruce 2011). We focus, in other words, on individual-level secularization rather than institutional differentiation or other types or meanings of secularization. We agree with Gorski and Altinordu (2008, p. 75) that, since we are focused on individuallevel secularization only in historically Christian countries, we could substitute "unchurching" or "de-Christianization" for "secularization" without any loss in meaning. Our point holds whether secularization is conceptualized as the undermining of religious belief and practice in modern societies or more narrowly as the undermining of traditional Christian beliefs and practices in historically Christian modern societies.

\footnotetext{
${ }^{6}$ Recent overviews of the secularization literature include Gorski and Altinordu (2008), Bruce (2011), and De Graaf (2013).
} 


\section{RELIGIOUS DECLINE IN THE UNITED STATES: A BRIEF OVERVIEW OF THE EVIDENCE}

Americans remain remarkably religious in both belief and practice, particularly as compared to people elsewhere in the West. The continuing high levels of American religiosity, coupled with the slow pace of decline, have made it easy to miss the signs of decline or to discount them when they are noticed. Here we briefly summarize the evidence that religious affiliation, attendance, and belief have been declining - if slowly - for several decades. A more detailed description of these and other trends can be found in Chaves (2011).

As is well known from coverage in the general media, the proportion of Americans who say that they have no religious affiliation has increased. This is a long-term trend, but the pace of change quickened substantially in the 1990s. In 1957, 3\% of Americans said they had no religious affiliation (U.S. Bureau of the Census 1958). By 2012, the figure had increased to 20\%, according to both the General Social Survey (GSS) and the Pew Research Center (2012). This increase reflects a growing willingness among the least religious people to say that they have no religion as well as a decline in meaningful attachments to religious traditions, but the cultural change is significant in either case. A society in which the least religious people still claim a religious identity is importantly different from a society in which such people admit to themselves, and even tell others, that they in fact have no religion.

Attendance at services began declining at least 15 or 20 years before the first GSS in 1972, at least among Catholics (Fischer and Hout 2006, pp. 2035 ). Time-use studies also register a decline in the decades before 1990, from approximately 40\% in 1965 to about 27\% in 1993 (Presser and Stinson 1998). This finding is reinforced by studies that track attendance trends among children and those that compare attendance rates among young people at different points in time (Hofferth and Sandberg 2001; Wuthnow 2007, p. 53). Average weekly attendance continued to fall slowly since 1990, and more extensive forms of involvement also have declined. The GSS occasionally asks people how often they participate in a religious congregation's activities beyond attending services. Seventeen percent of Americans said that they did so nearly every week or more in the 1990s, declining to $11 \%$ in the first decade of the 21 st century. The trend is the same for people who attend regularly.

At the same time, the number of people who never attend religious services has doubled in two and a half decades, going from $13 \%$ in 1990 to $26 \%$ in 2014. Much like the rising percentage of religious "nones," the rising percentage of people who never attend services mainly represents a change from a culture in which quite irreligious people still hold on to religious identities, even if religion has ceased to be personally significant, to one in which these people let go of those identities. 
Smith (2009) combined various surveys to show that while in the 1950 s $99 \%$ of Americans said they believed in God, that number dropped, slowly but steadily, to stand at $92 \%$ in 2008. It is $91.2 \%$ in the 2014 GSS, a figure that includes the responses "I don't believe in a personal God, but I do believe in a Higher Power of some kind" and "I find myself believing in God some of the time, but not at others." This decline is stretched out over five decades, but change has occurred. There is also a long-term, slow but discernible, decline in belief in an inerrant Bible. Over the last 30 years, the percentage of people who say they believe that the Bible should be taken literally declined from approximately $40 \%$ to just over $30 \%$.

These declines in traditional religiosity are not offset by increasing vitality elsewhere. It is true that the "spiritual but not religious" phenomenon has expanded in recent years. In 1998, 9\% of GSS respondents described themselves as at least moderately spiritual but not more than slightly religious. That number rose to $17 \%$ in 2014 . This increase occurred because nonreligious people are more likely to say that they are spiritual. This diffuse spirituality may provide a growing market for certain kinds of religious products, such as self-help books with spiritual themes, but it is not offsetting religious decline, reenergizing existing religious institutions, or providing a foundation for new kinds of religious institutions or new forms of religious collective action.

Relatedly, there is an increase in the number of people who say that they believe in life after death, but that increase has occurred especially among Jews and people who say that they have no religion (Chaves 2011, p. 38). This is best understood as an increase in a generic and diffuse spirituality rather than in traditional religious belief because the largest increases in belief in life after death are among the least religious Americans and among subgroups that have not traditionally emphasized an afterlife. There may be more diffuse spirituality now than previously, but it should not be mistaken for an increase in traditional religiosity. On the contrary, it is probably a consequence of the waning of traditional religiosity, every indicator of which is either stable or declining.

The evidence for a decades-long decline in American religiosity is now incontrovertible. Like the evidence for global warming, it comes from multiple sources, shows up in several dimensions, and paints a consistent factual picture. The American decline may be slower than in much of the West, and it might have started later than in some other places, but it is moving the society in a similar direction.

This decades-long but only recently visible decline in American religion should by itself give pause to those who want to claim that the United States is a counterexample to the secularization thesis. It might still be thought, however, that American religion is declining in a distinctive way. If, for example, American religion is merely suffering from a slump pro- 
duced by transient and peculiarly American historical circumstances, then perhaps it will turn the corner. If, however, the proximate causes of decline are similar to those observed elsewhere-including countries where religious belief and practice have been in decline for more than a century - then it is much harder to maintain that the United States is truly an exception to the secularization thesis.

In what follows we show that in a fundamental respect the American pattern of decline is remarkably similar to the pattern found throughout the West: the decline is driven by generational differences in religiosity. We focus on comparisons with other English-speaking countries: Great Britain, Australia, New Zealand, and Canada. We start with Great Britain because of obvious historical, linguistic, and cultural connections to the United States but also because Britain (where there are large Catholic and Protestant "free church" minorities, as well as smaller but now substantial nonChristian groups) has been religiously diverse for centuries, and the privileges enjoyed by Anglicans were largely eroded by the late Victorian period. $^{7}$ We include the other three countries because, in addition to sharing the English language (and in the case of Canada, the same continent), like the United States they were settled mainly by European immigrants. The truth, however, is that the pattern of religious decline in these countries has been very similar to that observed throughout Europe (Voas 2009), so our conclusions about similarities with the United States do not at all depend on choosing to focus on these particular cases.

\section{DATA}

We use the British Social Attitudes (BSA) surveys from 1983 to 2013, commissioned tables from the population censuses in Australia (1971-2011) and New Zealand (1986-2013), and the Canadian GSS, 1985-2012. In the United States, the GSS from 1972 to 2014 provides comparable data. In Australia and New Zealand, using census data means that we can examine only trends in religious affiliation in those two countries. We examine other available religious variables in the other countries, treating each measure in ways that are appropriate for each country, given data limitations. Since religiosity is multidimensional, and since multiple indicators of religiosity show the same basic pattern, using a range of available indicators is more appropriate than focusing only on items that are operationalized more or less identically in each country. Our strategy reinforces the point that our conclusions are not limited to any particular aspect of religiosity or way of operationalizing it.

${ }^{7}$ We refer to Great Britain rather than to the United Kingdom because our data do not include Northern Ireland. 
In Great Britain, the BSA survey is the main source for research on religious change. (The census now includes a question on religion, but that question appeared for the first time in 2001.) The survey has run annually since 1983, with gaps only in 1988 and 1992; it is conducted by NatCen Social Research using a random sample of more than 3,000 adults every year. ${ }^{8}$ There are lengthy face-to-face interviews with respondents, in addition to which self-completion questionnaires are left to be returned by mail. The data are made available by the U.K. Data Archive 12-18 months after fieldwork has concluded. Various topics are covered in depth each year, often as the result of funding from government departments or academic research projects. The relatively stable core includes questions on religious affiliation ("Do you regard yourself as belonging to any particular religion?") and attendance ("Apart from such special occasions as weddings, funerals and baptisms, how often nowadays do you attend services or meetings connected with your religion?").

In Australia, a population census is conducted every five years by the Australian Bureau of Statistics. Although a question on religious affiliation has been included since the early 20th century, the possibility of specifying "no religion" has been explicit only since 1971, before which less than 1\% of the population was so recorded. The question on religion is optional, but it is answered by about $90 \%$ of the population. ("Not stated" cases are omitted in the analysis.) Respondents were originally asked to write in a religion or "none," but in 1991 the form was changed to provide a list of the main denominations, which as discussed below produced a modest rise in the level of affiliation. Relevant tables were commissioned from the Australian Bureau of Statistics.

New Zealand also carries out a population census every five years. The data collection that was scheduled for early March 2011 was postponed when a major earthquake struck Christchurch, the country's second-largest city, two weeks before the census date. A replacement census was conducted in March 2013. The answer format changed in 1986, producing a substantial rise in the proportion choosing to identify with no religion; only censuses since that date are used here. For censuses from 2001, individuals have been allowed to select up to four responses to the religion question, although only $4 \%$ in 2001 and $2 \%$ in 2006 and 2013 chose more than one. In the analysis that follows, multiple responses and nonresponses are excluded. Special tables were commissioned from Statistics New Zealand to include country of birth, to separate single and multiple responses, and to provide nonstandard age groups for 2013 (when the gap since the previous census was seven rather than five years).

\footnotetext{
${ }^{8}$ The sample includes adults age 18 and over; for the reasons set out in $\mathrm{n} .9$ and to be consistent across countries, we restrict our attention to respondents age 20-84.
} 
The GSS in Canada began in 1985 and is conducted by Statistics Canada, the national statistical agency. Data are gathered by telephone. The sample consists of individuals age 15 and older, but our analyses include only adults age 20 and older. No surveys were carried out in 1987 or 1997; in addition, the 2002 and 2007 surveys sampled only persons age 45 and older. We exclude those years. Sample sizes range between 10,000 and 25,000; response rates have been $70 \%-80 \%$. The public use microdata files sometimes supply single years of age but for most years categorize age in fiveyear bands. Where necessary, the totals in each age group were distributed pro rata in constructing the 10-year birth cohorts shown below in figures 5-7.

Questions on religious affiliation and attendance have been included since the inception of the survey, and a new question on the importance of religious or spiritual belief was introduced in 2003. Until recently only respondents who stated a religious affiliation were asked about attendance, so our data on religious practice are restricted to people who say that they have a religion. In addition, respondents who answered the question "How important are your religious or spiritual beliefs to the way that you live your life?" with "not at all important" were not asked about attendance in 2003 and 2004. We have imputed a value of "less than monthly" for this group.

The GSS in the United States is run by the National Opinion Research Center at the University of Chicago and involves face-to-face interviews with a random sample of noninstitutionalized adults age 18 and over (Smith, Marsden, and Hout 2015). It was conducted annually from 1972 until 1994 (except in 1979, 1981, and 1992) and every other year since then. Sample sizes for each survey range from approximately 1,500 to approximately 3,000. Questions on religious affiliation and attendance have always been part of the survey, although the question on strength of religious affiliation was only introduced in 1974. A question on belief in God (with six answer categories) first appeared in 1988. We exclude the black oversamples from 1982 and 1987 . We restrict our analysis to individuals age 20-84. ${ }^{9}$

\section{METHODS}

Our primary empirical claim is that generational differences are driving religious decline throughout the West. Establishing this claim requires us to grapple with the thorny issue of how to distinguish generational change from changes related to aging and from changes produced by historical

\footnotetext{
${ }^{9}$ The GSS sample includes individuals age 18 and over. We omit 18- and 19-year-olds because survey nonresponse tends to be high among young adults, making teenage respondents unrepresentative, and also because religious identity and practice have often not stabilized until the early 20s. We are concerned in addition that at advanced ages the sample may become unrepresentative, and so we omit respondents age 85 and over.
} 
developments that affect all generations. This is the notorious age-periodcohort (APC) problem that has vexed sociologists at least since Ryder's landmark article (1965). Recent attempts to disentangle age, period, and cohort effects have tackled topics as diverse as fertility (Bongaarts and Sobotka 2012), sexual mores (Kraaykamp 2002), trust (Robinson and Jackson 2001), civic participation (Van Ingen 2008), alcohol consumption (Karlamangla et al. 2006), and happiness (Yang 2008). Religion has not escaped attention (Voas and Crockett 2005; Wolf 2008; Schwadel 2010a, 2010b, 2011, 2013).

The fundamental methodological challenge is posed by what is known as the APC identification problem, which arises because any two of the factors determine the third (e.g., age = year of observation - year of birth). There has been persistent confusion among social scientists over the nature of this problem, caused in part by preoccupation with the methodological difficulties that arise in trying to use all three factors as independent variables in multivariate analysis. This preoccupation leads people to overlook the more fundamental substantive problem, which is the difficulty in deciding which effect, or combination of effects, explains what is observed. Solving the identification problem does not equate to solving the substantive problem: model identification is not equivalent to identifying the actual effects. Glenn made this point very forcefully: "The continued search for a statistical technique that can be mechanically applied always to correctly estimate the effects is one of the most bizarre instances in the history of science of repeated attempts to do something that is logically impossible" (2005, p. 6).

We proceed in three steps, beginning with graphical examination of the data. Generally the most helpful representations are graphs in which the vertical axis is the level of religious involvement (e.g., the percentage of respondents who say they attend religious services at least monthly) and the horizontal axis is survey year, with separate lines plotting each birth cohort's religiosity as it ages. ${ }^{10}$ Our graphs' vertical axes do not all show the same range of possible values because we want to scrutinize betweenand within-cohort changes in each country, a goal that is best achieved by a flexible treatment of these axes. Thus, differences across countries and indicators are not visually emphasized in our graphs, but these differences in levels of religiosity are easily discerned by reading the values on the vertical axis.

Our second step is to employ Firebaugh's technique for decomposing aggregate change into between- and within-cohort components (Firebaugh and Davis 1988; Firebaugh 1989, 1997). Finally, we combine the graphical

${ }^{10}$ We plot a point on the graph for the birth cohort only if the number of respondents in that cohort in a particular year passes a threshold value, which for the United States is set at 100 . 
evidence and decomposition results with established substantive knowledge and common sense to draw conclusions about what combination of age, period, and cohort effects most likely produced the patterns we observe. Because there are always different APC combinations that are consistent with the data (the essence of the identification problem), it is important to consider alternative possibilities, which we do. As readers will see, taken together, the graphical evidence, decomposition results, and established substantive knowledge lead us to strongly favor a cohort-replacement explanation over alternative interpretations that could, as logical possibilities, have produced the observed patterns.

We have deliberately chosen not to rely on more elaborate statistical techniques, all of which have been subject to methodological criticism. In the past decade, the cross-classified multilevel model (Yang and Land 2006, 2013a) and the intrinsic estimator (Yang, Fu, and Land 2004; Yang et al. 2008; Yang and Land 2013a) have come to be seen as the state-of-theart tools of choice for APC analysis, but criticisms have recently been leveled against these methods (Luo 2013; Luo and Hodges, forthcoming; Bell and Jones 2014; Pelzer et al. 2015). Fortunately for our analysis, we do not need to take sides in this debate because even the main proponents of these techniques acknowledge that they are not a universal solution to the identification problem and there are situations in which they are not appropriately used (Yang and Land 2013b, p. 1971). Religious change is one such situation: whether we rely on statistical parsimony or substantive knowledge and common sense, our data can be adequately described using a single- or two-factor model.

We therefore sidestep the statistical debates by using methods that are intuitive and transparent. In the case at hand we believe that a relatively simple approach making use of substantive knowledge and judgment is preferable to mechanical model specification and estimation. Readers can examine the visualizations and the supporting decompositions and decide for themselves whether alternative interpretations of the evidence are plausible.

Firebaugh's decomposition technique is appropriate here, however, because rather than trying to isolate all three possible effects - cohort, age, and period - it distinguishes aggregate change produced by cohort replacement from aggregate change produced by change at the individual level. Individual change could of course be related to aging or to period, and we offer observations about various interpretive possibilities. But our core concern is to establish the importance of cohort differences in religiosity, and this technique is well suited to that task. Details on how we apply it can be found in the appendix.

We should mention one other methodological issue. Using censuses or repeated cross-sectional surveys to investigate religious change within and 
across generations involves tracking birth cohorts over time. Since our focus is on endogenous social change, the composition of these groups needs to be fairly stable. If the population is being refreshed by immigration, these compositional changes will obscure any shifts in the previously resident population. We therefore focus on the native-born populations of Australia, New Zealand, Canada, and the United States. ${ }^{11}$ Country of birth was not included in the BSA surveys until recently, and so as a proxy for native British status we consider just respondents of white ethnicity.

The impact of immigration on a society's religiosity is an important issue in its own right, but generational change can be pushing religiosity down in a society even if immigration pushes in the opposite direction. Our objective is to establish the extent to which cohort replacement contributes to religious change, and focusing on the native born is the best way to do that. At the same time, since U.S. immigration history is often invoked as a reason for ongoing high levels of religiosity in the United States, we confirmed that our key results and conclusions do not change if we take immigrants into account. We say more about this issue at the end of the results section.

\section{RESULTS}

The Generational Dynamics of Religious Decline in Four Countries

\section{Great Britain}

As figure 1 shows, religious affiliation in Great Britain has declined from one cohort to the next for years of birth going back to the beginning of the 20th century. The largest drops occurred among people born after the Second World War, particularly in the early postwar decades. There is remarkable stability over the adult life course for all generations. The changes that have been observed in total religious adherence arise entirely from differences between rather than within cohorts. The first line of decomposition results in table 1 further supports this conclusion. The key number is in column 11, which shows the cohort replacement effect from the linear decomposition model. The model implies that cohort replacement would have decreased religious affiliation in Great Britain by 21.3 percentage points, close to the observed decline of 20.2 percentage points (col. 5).

Age and period effects are not obvious in either figure 1 or table 1, if they exist at all (Voas and Crockett 2005; Crockett and Voas 2006). While they might be present but completely offsetting, we do not find this alternative

\footnotetext{
${ }^{11}$ Respondents were only asked whether they were born in the United States from 1977 onward. For earlier years, and where there are missing values on the nativity question, we treat being resident in the country at age 16 as a proxy. We estimate that fewer than $2 \%$ of resident-at-16 respondents for the years 1973-76 would have been born abroad.
} 


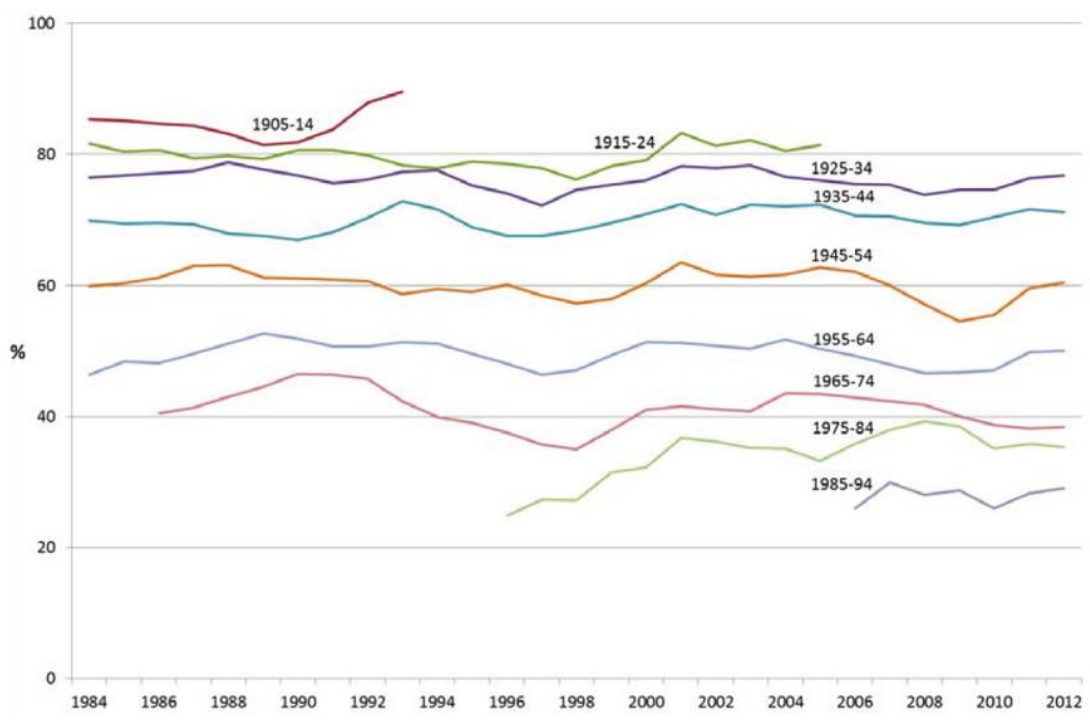

FIG. 1.-Religious affiliation by decade of birth, Great Britain, 1983-2013. Data are from the British Social Attitudes survey, 1983-2013. Includes white respondents age 2084. Three-survey moving average.

hypothesis plausible. In the first place, it seems more credible that age and period effects are weak or nonexistent than that they are strong but perfectly balanced. The longer the period, the more surprising it would be to maintain this balance, and the BSA series has been running for three decades. Similarly, it seems highly unlikely that age and period effects would be completely offsetting everywhere, yet a similar pattern is observed in all of the countries we study here as well as others that we do not examine in this article. If there is a tendency for adults to become more religious as they grow older, age effects should be apparent somewhere.

Second, the mechanism that produces cohort effects is straightforward: we are socialized by the religious environment of our upbringing, and members of each successive cohort in Great Britain (and elsewhere in the West) are less likely to have been raised in religious households and are therefore less likely to be religious as adults. By contrast, perfectly counterbalancing age and period effects would imply that each person faces an ongoing struggle between proreligion forces associated with aging and antireligion external forces that continuously fight to a more or less perfectly balanced standoff. Struggle of this sort is not apparent.

Third, if the age and period trends were in balance, the cohort lines would be equidistant from each other. The fact that they are not would require there to be cohort effects operating alongside the period decline. In 


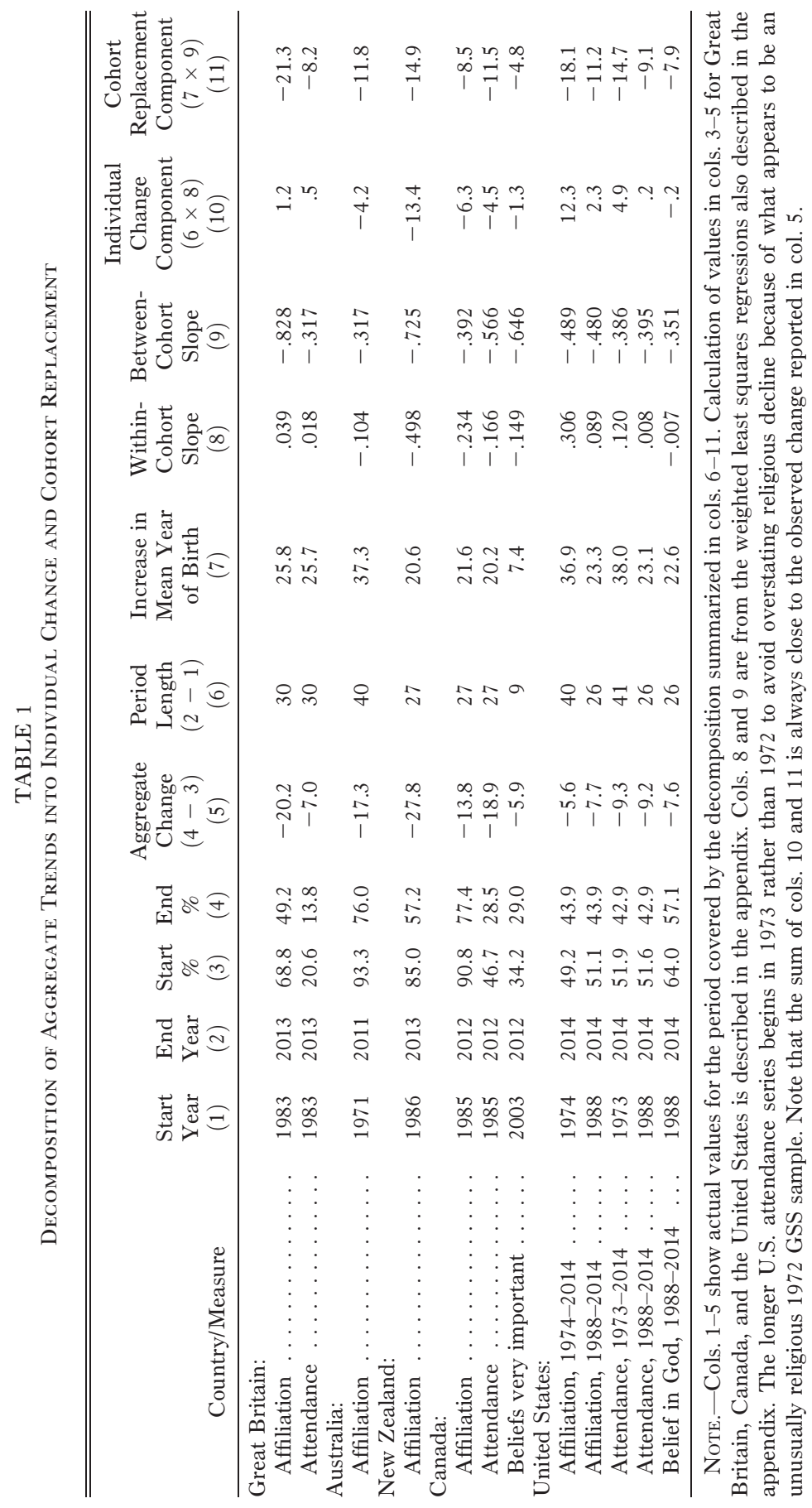

This content downloaded from 128.041.061.070 on March 11, 2016 04:48:40 AM All use subject to University of Chicago Press Terms and Conditions (http://www.journals.uchicago.edu/t-and-c). 
order to adjust the cohort starting points appropriately, these effects would sometimes be positive and sometimes negative. The combination of a constantly negative and strong period effect with cohort differences that sometimes are positive and sometimes negative seems extremely unlikely. It is much more likely that irreligious times produce irreligious generations and vice versa. By contrast, if cohort differences are mainly responsible for religious change, the varying size of the generation gap can be explained much more plausibly by modest variations in the rate of intercohort decline in religious socialization.

Finally, we would expect that any age effects on religious affiliation come about because of life-course events like setting up a home independently, marrying, having children, or retirement. Age effects are therefore unlikely to be perfectly linear over an adult lifespan. Figure 1 shows no sign of substantial event-based shifts in religious affiliation, however. If perturbations produced by life-course events are ironed out by compensating period and cohort effects, the combinations required become improbably complex.

All in all, therefore, the most straightforward explanation of the pattern evident in figure 1 and the first line of table 1 is that declining aggregate religious affiliation in Great Britain is driven by cohort replacement. Logically possible alternative explanations can be devised, but no alternative explanation seems plausible in light of common sense and established knowledge about correlates of religious affiliation. This same reasoning applies in essence to the patterns for all of the religious variables in all of the countries we examine.

Although it has been conventional in the United States to study weekly attendance, we focus on attendance monthly or more often in this study. We do so because we are interested in the size of the more or less regularly worshipping community rather than in the number of people who claim never to miss a week. This strategy also allows us to sidestep the possibility that declines in weekly attendance exaggerate the decline in the churchgoing population because a shift from attending weekly to once or twice a month does not represent an exit from religious involvement.

As figure 2 shows, the patterns for attendance are similar to those for affiliation. Once again the substantial contrast is between the generation born before the First World War (among whom 30\% were churchgoers) and the youngest adult cohort (among whom the figure is around 7\%). Although there is a certain amount of noise in the year-to-year results, most cohorts show little net change in attendance levels over the three decades covered by these surveys. On average, people from a particular decade of birth in Britain do not seem to become much more religiously active with age, nor have they become less active over time. Religious decline is being driven by generational replacement, as confirmed again by the decomposition shown in table 1 . As with affiliation, the cohort replacement com- 


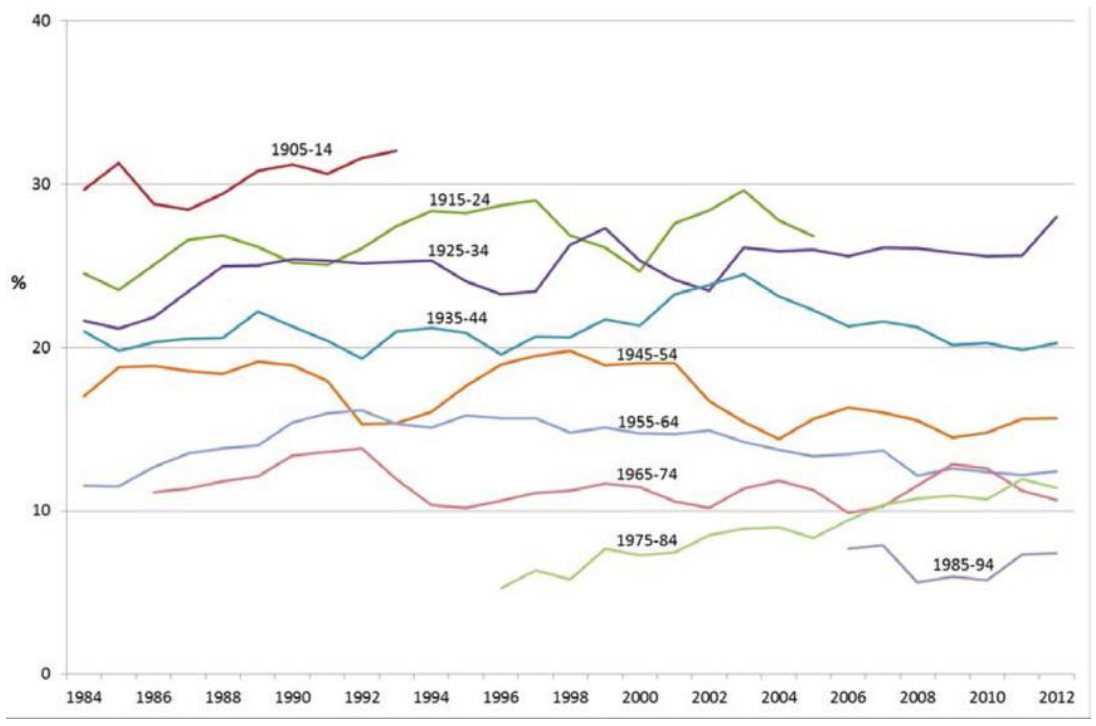

FIG. 2.-Attendance at least monthly by decade of birth, Great Britain, 1983-2013. Data are from the British Social Attitudes survey, 1983-2013. Includes white respondents age 20-84. Three-survey moving average.

ponent of declining attendance in Great Britain (8.2 percentage points) is slightly larger than the observed aggregate change (7.0 points).

The BSA survey included a question on belief in God (identical to the one described below for the United States) for a subsample in several years between 1991 and 2008. The small sample sizes on these items preclude producing graphs like figures 1 and 2, but the contrasts between successive cohorts are very clear. Among white respondents born between 1905 and 1924, 58.5\% across all survey years reported either that "I know God really exists and have no doubts about it" or "While I have doubts, I feel that I do believe in God." Only $17.2 \%$ of adults born in the late 1980s said the same. And whereas most of the older believers chose the "no doubts" option, younger theists do not have the same level of conviction.

\section{Australia}

The situation in Australia is similar. The generational contrast emerges clearly in the proportion of people identifying with no religion in the 2011 census: only $9 \%$ of those age 80 and over but $33 \%$ of those in their 20s, notwithstanding the immigration of young non-Christians. Figure 3 shows the full cohort pattern. The proportion of people identifying with a religion diminishes in each successive decade of birth, and because the census counts 


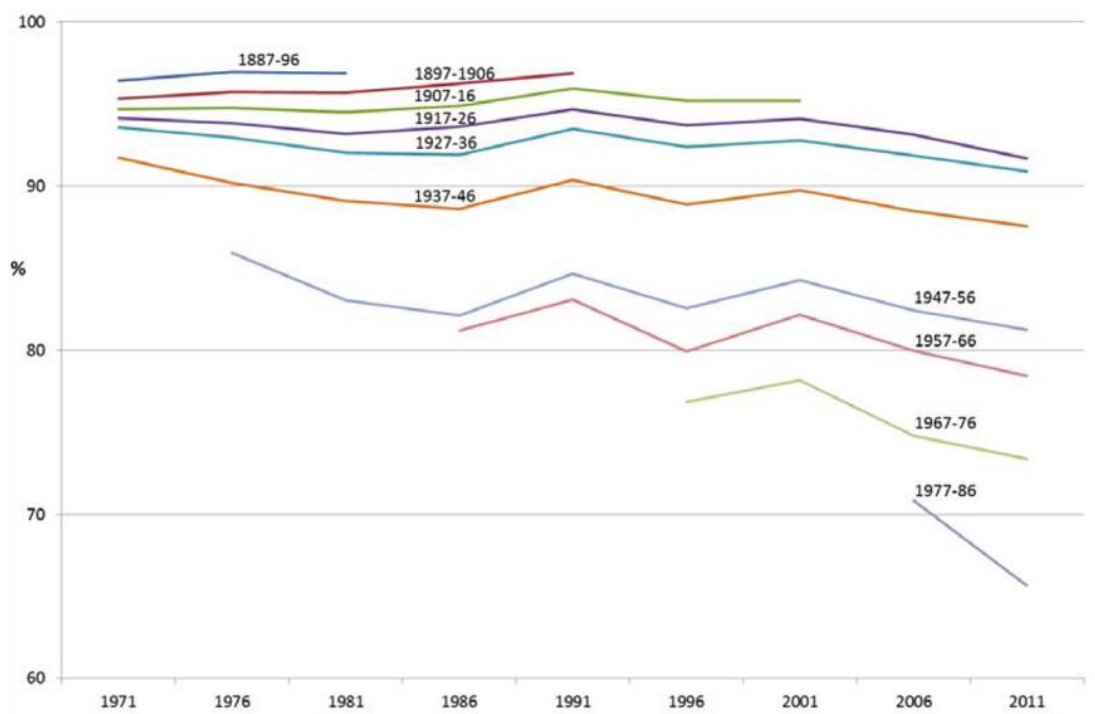

FIG. 3.-Religious affiliation by decade of birth, Australia, 1971-2011. Data are from the Australian Bureau of Statistics: commissioned tables from the census of population, 1971-2011. Includes only people born in Australia.

are very large, it is possible to look back to people born as early as 1887 . Over the four decades covered by the data there are only weak signs of change within generations, such as might be produced either by aging or by historical events.

The graphs undulate slightly, with peaks in 1991 and 2001. It is possible that something in the cultural context led to these rises and falls in religious identification, but these fluctuations could also be measurement artifacts. As mentioned above, in 1991 the census form provided check boxes for the most common denominations rather than requiring write-in responses. One striking consequence was that the number of native-born Presbyterians age 20 and over increased by a third from the 1986 total. (By implication, a quarter of self-identified Presbyterians in 1991 were so nominal that they would have been unwilling or unable to spell out the name of their denomination.) Catholic, Anglican, and Uniting Church numbers received more modest boosts. It is less clear what might have caused the rise in 2001, although the fact that the 70,500 people giving "Jedi" as their religion were classified as "undefined" rather than "none" may account for some of it.

Overall there is little here to suggest that period, let alone age, had substantial effects on religious affiliation in Australia before 2001. The most significant departure from intragenerational stability comes in the most recent census in 2011, when the graphs suggest that there has been within- 


\section{American Journal of Sociology}

as well as between-cohort decline. The large gap between the two youngest cohorts (people born 1967-76 and 1977-86) is consistent with the conjecture that important secularizing forces have continued to operate. The largest previous drop is associated with the cohort born in 1947-56, which would have entered adolescence during the 1960s. The decomposition results in table 1 suggest that three-quarters of the aggregate change between 1971 and $2011(11.8 /[11.8+4.2]=.74)$ was produced by cohort replacement, with individual disaffiliation accounting for the remainder.

\section{New Zealand}

In New Zealand, $42 \%$ of the population stated on the 2013 census that they have no religion. Here too the trend is clear: the figure stood at $20 \%$ in 1991 , at $30 \%$ in 2001 , and at $35 \%$ in 2006 . Figure 4 , which divides the native-born population into five-year birth cohorts, shows the steadiness of intergenerational decline. Among the elderly, Christian affiliation exceeds $85 \%$, and "no religion" is in single digits. Young adults, by contrast, are about equally split between those claiming a Christian affiliation and those claiming no religion. People born in each half decade throughout the 20th century are a little less likely to have a religion than those born just five years earlier.

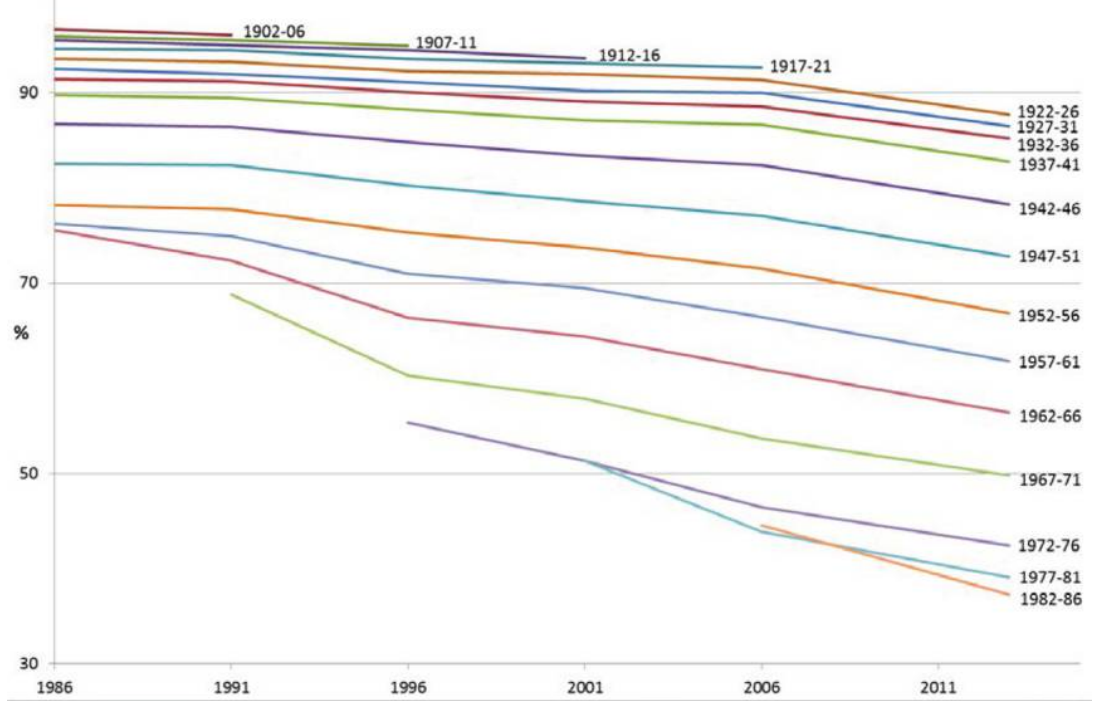

FIG. 4.- Religious affiliation by five-year birth cohort, New Zealand, 1986-2013. Data are from Statistics New Zealand; commissioned tables from the Census of Population and Dwellings, 1986-2013. Includes only people born in New Zealand. 
As in Australia, the rate of change increases with cohorts born during and after the Second World War and does not slow until the group born between 1977 and 1981. Also as in Australia, a slight erosion in religious identity can be seen within as well as between cohorts, and these effects are most evident for the younger cohorts, producing some fanning out in the graphs during the later periods. Nevertheless, the main shifts are from one generation to the next, with relative stability within each. The statistical decomposition in table 1 shows that cohort replacement is responsible for the majority of the aggregate decline, reinforced by within-cohort change in the same direction $(14.9 /[14.9+13.4]=.53)$.

\section{Canada}

In Canada, reported weekly church attendance was a staggering $67 \%$ in 1946 (Veevers and Gee 1988, p. 18). It has been falling steadily ever since and stood at $17 \%$ in 2012 , although because of overreporting, the true figure is at best half as high (Brenner 2012). In 2012, nearly half (48\%) of people born in Canada said that they never attend.

Figure 5 shows that between-cohort decline in religious affiliation in Canada was modest among people born before the Second World War, but the now-familiar pattern is clear thereafter. Within-cohort decline is also

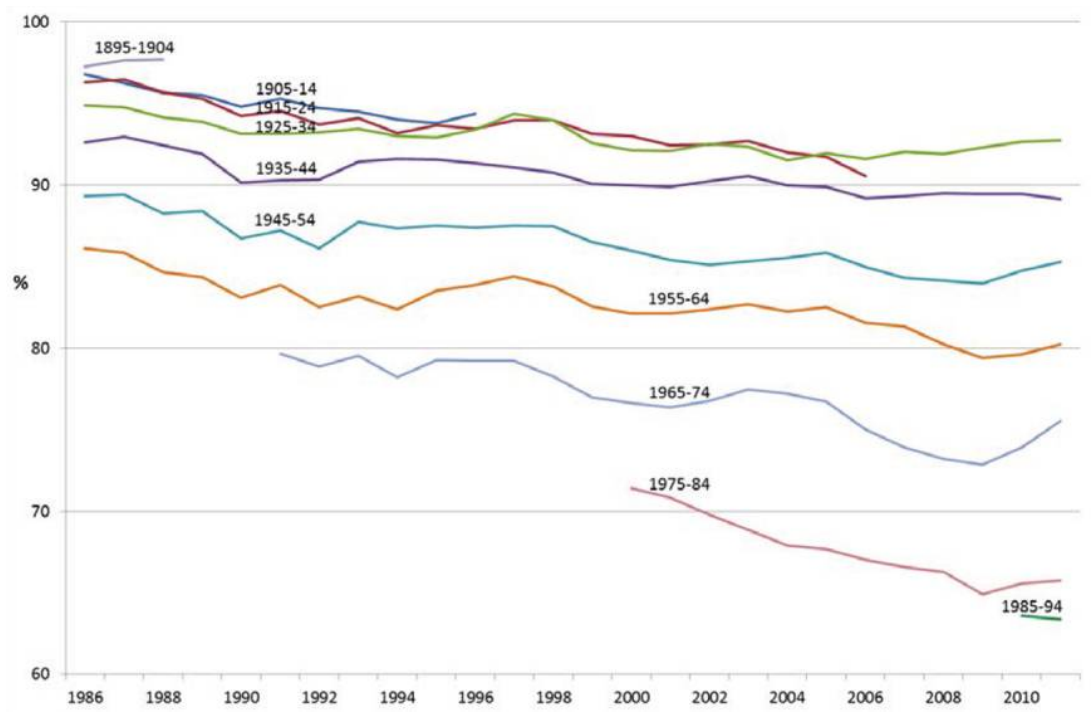

FIG. 5.- Religious affiliation by decade of birth, Canada, 1985-2012. Data are from the Canadian General Social Survey, 1985-2012; includes only respondents born in Canada. Three-survey moving average. 
apparent, and as in New Zealand the rate of decline seems to increase with year of birth. This fanning out of the cohorts for later survey years may indicate a period effect, but another interpretation is that religious affiliation drops during early adulthood before becoming more stable.

Figure 6 shows monthly attendance at services for people who say that they have a religion. (Until recently, only respondents who stated a religion were asked about attendance in the Canadian GSS.) Given the generational decline in affiliation, one would not necessarily expect to find substantial differences between cohorts in the proportion of churchgoers among those who remain religiously affiliated. After all, once overtly secular respondents are excluded, religious practice might be equally frequent among the young and the old. In fact, the differences are substantial: religious affiliates age 70 and above are twice as likely as adult affiliates less than 60 to attend at least monthly (41\% vs. $18 \%$ in 2012 ) and three times as likely to attend weekly (29\% vs. $10 \%)$. We do see a bottoming out, however. Among people born since 1955 who identify with a religion, year of birth makes little difference to the proportion of regular attenders. Recall, however, that the proportion of affiliates has fallen substantially across these postwar cohorts. The bottoming out of cohort differences in attendance among affiliates should not be interpreted as a slowing down of cohortdriven secularization in Canada.

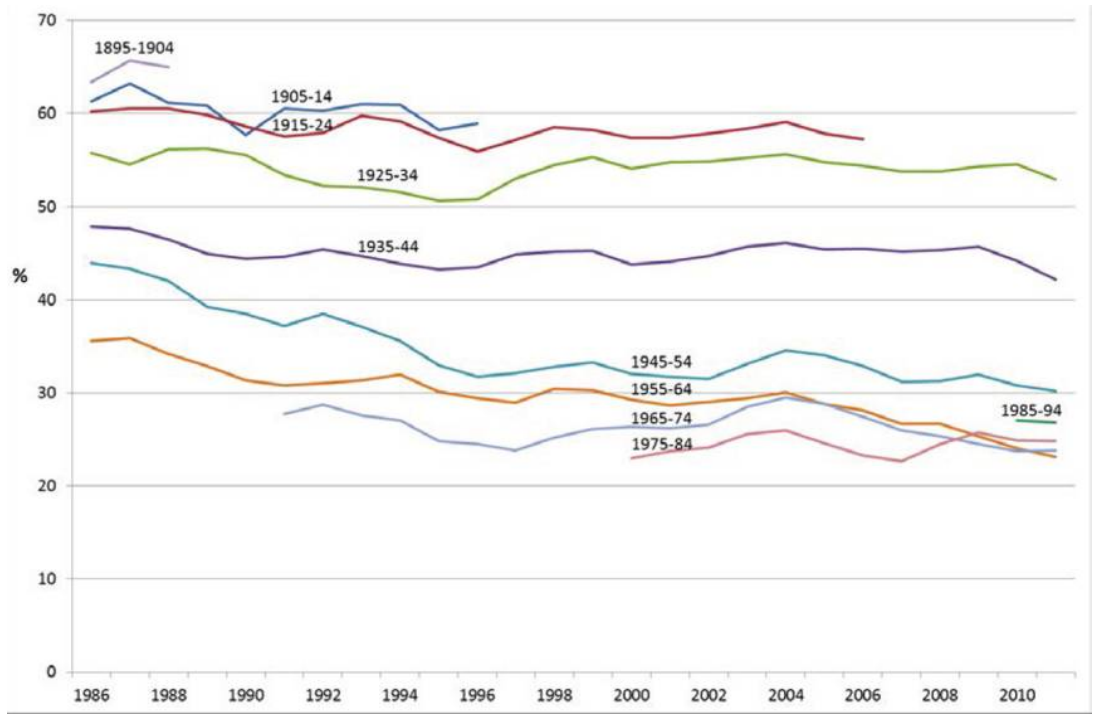

FIG. 6.-Monthly attendance by decade of birth (religious affiliates only), Canada. Data are from the Canadian General Social Survey, 1985-2012. Includes only respondents with a religious affiliation who were born in Canada. Three-survey moving average. 


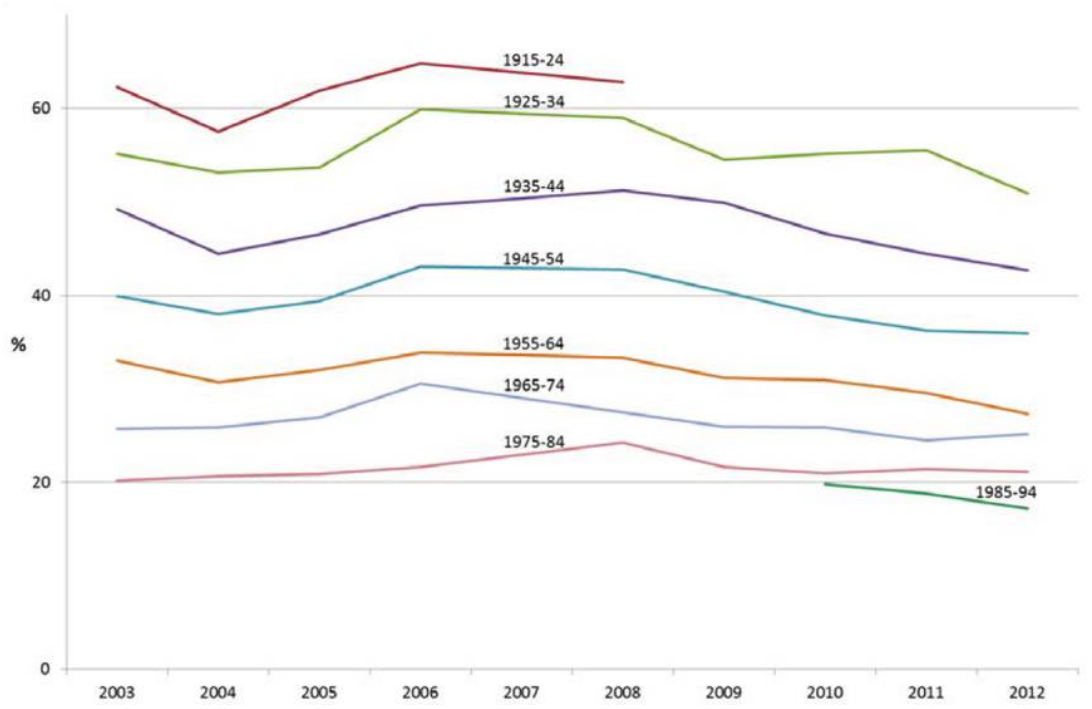

FIG. 7.--Religious or spiritual beliefs "very important" in life, by decade of birth, Canada. Data are from the Canadian General Social Survey, 2003-12; includes only respondents born in Canada.

Taken together, figures 5 and 6 suggest that secularization in Canada proceeded in stages. Members of the 1925-34 cohort started to drift away from regular involvement in religious activity while still retaining their religious identities. Among people born just before and after the Second World War, we see a combination of disaffiliation and reduced involvement. For years of birth from about 1955 onward, further religious decline has come from people taking the step of not identifying with a religion at all. The decomposition results in table 1 show that most of the drop in affiliation is the result of cohort replacement $(8.5 /[8.5+6.3]=.57)$, but within-cohort declines also have been substantial $(6.3 /[8.5+6.3]=.43)$. The drop in monthly attendance by affiliates is even more strongly cohort based. ${ }^{12}$

Figure 7 looks beyond whether people say they have a religion, go to church regularly, or believe in God, to examine how much difference people say these things make in their lives. In 2003, the Canadian GSS began asking: "How important are your religious or spiritual beliefs to the way you live your life?" The response options were very/somewhat/not very/not at all important. Figure 7 shows the steady fall from one decade of birth to the next in the proportion of respondents answering "very important." Al-

${ }^{12}$ The fall in weekly attendance among affiliates is entirely cohort driven (results available on request). 
though the period covered is only nine years, the comparative unimportance of within-cohort trends is noteworthy, as confirmed by the decomposition results in table 1, where cohort replacement accounts for four-fifths of the observed aggregate decline $(4.8 /[4.8+1.3]=.79)$. Even with no smoothing, the lines in figure 7 are virtually horizontal. By contrast, the amount of intergenerational change is dramatic, with more than $60 \%$ of the oldest and less than $20 \%$ of the youngest cohorts describing religion as very important.

\section{Recap}

The central result for Great Britain, Australia, New Zealand, and Canada is easy to state: secularization has occurred mainly, in some cases entirely, because each successive generation is slightly less religious than the one before. At an aggregate level, religious indicators across the adult life course within each cohort are remarkably stable in these countries. Individuals might become more or less religious, but within birth cohorts these gains and losses largely balance out. If there is a tilt, it is toward people becoming somewhat less religious over time. We have highlighted the English-speaking world, but the basic pattern is not restricted to these countries. Analyses of religious decline in dozens of European countries also point to the dominant role of cohort replacement (Wolf 2008; Voas 2009; Voas and Doebler 2011).

Moreover, these results do not depend on examining particular indicators of religiosity or shifts in a particular region of the religiosity distribution. The basic results are the same whether we examine affiliation, attendance, or belief in God. And they are unchanged if we look at the proportion of people who attend either more or less frequently or if we look at religious beliefs being at least somewhat important rather than not important. Cohort replacement dominates the trends whatever indicator we examine and whether we look at shifts from high to moderate or moderate to low religious commitment.

As discussed above, solutions to APC problems are not unique. Alternative hypotheses could be advanced. In particular, a period decline in religious involvement offset by increasing religiosity with age could generate patterns resembling those produced purely by cohort effects. For the reasons discussed above, however, this interpretation seems much less plausible than the one we advance. Various combinations of age and period effects are consistent with the intracohort change that we observe, but our central concern is to distinguish cohort replacement from intracohort change, not to parse out different components of intracohort change.

We conclude that cohort replacement is the primary driver of religious decline in these countries. We now turn our attention to the United States, where we show that the same is true. 
The Generational Dynamics of Religious Decline in the United States

It was long thought that the United States was exempt from religious decline, but the evidence reviewed earlier points to a different conclusion. In what follows, we show that there also is a deeper sense in which the country is not an exception to the pattern of secularization observed throughout the West: declining religiosity has been driven by generational change.

\section{Affiliation}

Among people born after 1975, declared affiliation in 2014 was a full 23 percentage points lower than among those born before 1935 (71\% vs. 94\%). Gaps between the cohorts born before 1945 are very small; the major shift toward no religion begins with the baby boomers, and the erosion in religious affiliation continues in later generations, reinforced since 1990 by what appears to be a period effect in which individuals in every cohort, but especially the younger ones, have disaffiliated. A considerable amount of attention has been paid to this "rise of the nones," revealed not only in the GSS (Hout, Fischer, and Chaves 2013) but also in the American Religious Identification Surveys (Kosmin and Keysar 2009), in surveys carried out by the Pew Research Center (2012), in the Baylor Religion Survey (Baker and Smith 2009), and by Gallup polls (Newport 2012).

Rather than reproduce well-known results about the "nones," we take a different tack in our analysis of affiliation trends in the United States. Since 1974, the GSS question on religious preference has been followed by one that asks "Would you call yourself a strong X or a not very strong X?" where $\mathrm{X}$ is the group chosen. Although the question is posed as a binary choice, answers of "somewhat strong" are coded; about one in 10 respondents volunteers this description of his or her affiliation. By distinguishing strong or somewhat strong affiliation on the one hand from no affiliation or a not very strong one on the other, we divide the population almost exactly in half.

We prefer this approach because, when nominal adherence is very high, as it is in the United States, being particularly attached to a religious identity is more sociologically meaningful than the mere fact of having an affiliation. Respondents whose affiliation is "not very strong" are more similar in their religious involvement to the unaffiliated than they are to those with strong religious identities. Only $8 \%$ report attending religious services at least weekly, a figure that is far closer to the $2 \%$ of frequent attenders among the "nones" than to the $51 \%$ of frequent attenders among the strongly affiliated. Moreover, renouncing any religious identity is a high bar, and relatively few people born before the end of the Second World War reached this threshold of secularity. As we mentioned above, there was hardly any change before the baby boom generation in the proportion of Americans 


\section{American Journal of Sociology}

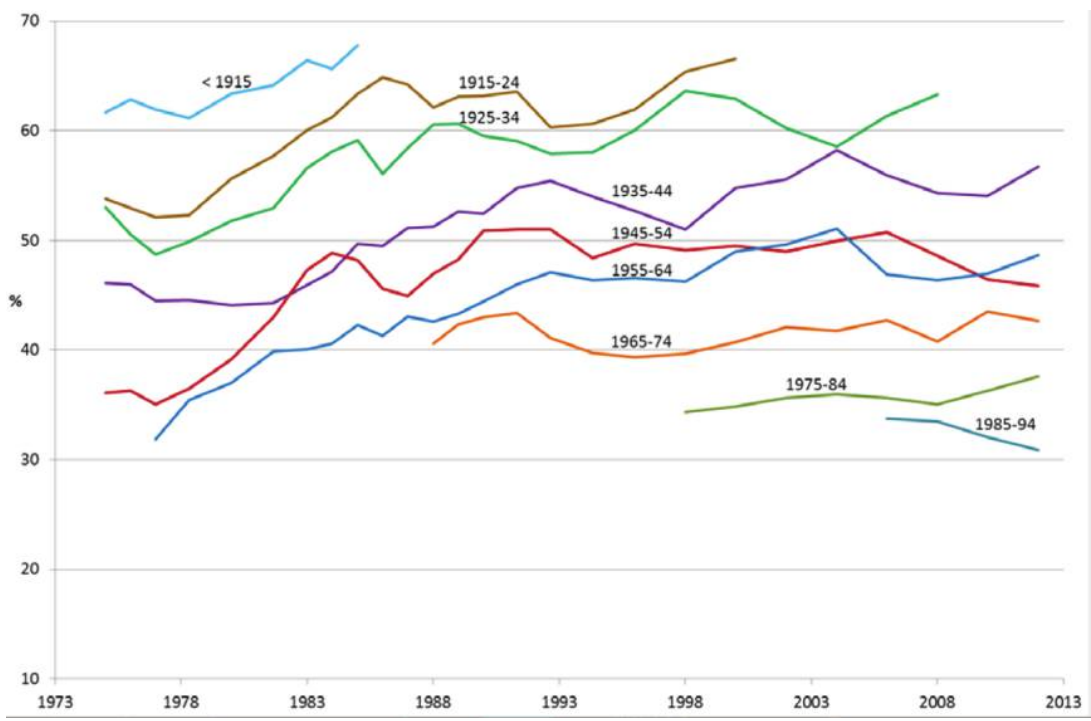

FIG. 8.-Strong or somewhat strong religious affiliation by decade of birth, United States, 1974-2014. Data are from the General Social Survey, 1974-2014. Includes respondents age 20-84 born in the United States. Three-survey moving average.

saying they have no religion. By contrast, figure 8 shows that strong affiliation in fact weakened for every successive generation from as far back as we can see, to people born more than a century ago. We cannot be certain that individuals born around the time of the First World War, who reached adulthood before and during the Second World War, were less religious than their parents, because the GSS only began in the early 1970s. It seems very likely, however, that the generation gaps observed at that point already existed in the first half of the 20th century. The alternative hypothesis - that the gap only opened up when these people were middle aged-seems less plausible. ${ }^{13}$

The pattern of substantial and negative cohort differences is evident across all survey years. Unlike the other countries we have examined, there seems to have been a period, running roughly from 1978 to 1988, in which strong affiliation rose by about 10 percentage points in every birth cohort. Attendance also increased in these years, as we note below. It seems that

\footnotetext{
${ }^{13}$ The cohort pattern is the same if we use the more conventional affiliated-versus-not distinction except that, for reasons noted in the main text, the very oldest cohorts appear more similar to each other than they do in fig. 8. Hout and Fischer (2014, p. 428) conclude that "two-thirds of the increased tendency to declare no religion is rooted in generational succession."
} 
a cultural shift in this period increased religious involvement. This 1980s religious revival was recognized as early as 1989 (Chaves 1989). Putnam and Campbell (2010) interpret it as a reaction to the social upheavals of the 1960s and early 1970s. Whatever its cause, the revival ran its course by the end of the Reagan presidency, and very little change within cohorts is apparent subsequently.

Although the period covered by the GSS over the mid- to late 1970s is very short, there are modest within-cohort declines in strong affiliation (and, for that matter, in having a religion as opposed to none, for which we have data starting two years earlier). Perhaps the 1980s religious revival mainly involved the recovery of individuals lost during the preceding decade or two. If so, the 1980s simply corrected for the unusually irreligious $1960 \mathrm{~s}$ and 1970s.

In any case, cohort replacement eroded religious affiliation throughout the past four decades. This is the key point. Looking at the period as a whole (line 8 of table 1), cohort replacement would have reduced strong religious affiliation by 18.1 percentage points were it not for the offsetting intracohort increases, especially during the 1980s. When we decompose the change just since 1988 (line 9 of table 1), only a fifth of the impact of cohort replacement is offset by positive within-cohort change. The very slight upward drift within cohorts may represent a consolidation of religious identity with age. In view of the continuing and substantial decline from one generation to the next, it seems unlikely to be a period effect.

As has been seen in detail for other English-speaking countries, and as other research shows is the case throughout the West, cohort replacement has been pushing strong religious affiliation downward in the United States. Countervailing within-cohort increases, especially during the 1980s-increases not found elsewhere, except in Italy (Vezzoni and Biolcati-Rinaldi 2015) - have partially disguised this fundamental similarity in the underlying dynamics.

\section{Attendance}

We saw earlier that involvement in American religious congregations, which mainly means attendance at worship services, has declined. The analysis that follows shows that decline in attendance is driven by the same cohort replacement mechanism that drives attendance declines elsewhere in the world. For the reasons mentioned above for Great Britain, we examine the proportion of GSS respondents who say they attend at least once per month. Note that "once a month" was the median response until 1993. Since 1994 the median response has been "several times a year."

The attendance pattern in figure 9 is very similar to the affiliation pattern we saw in figure 8. Gentle decline within cohorts during the 1970s was 


\section{American Journal of Sociology}

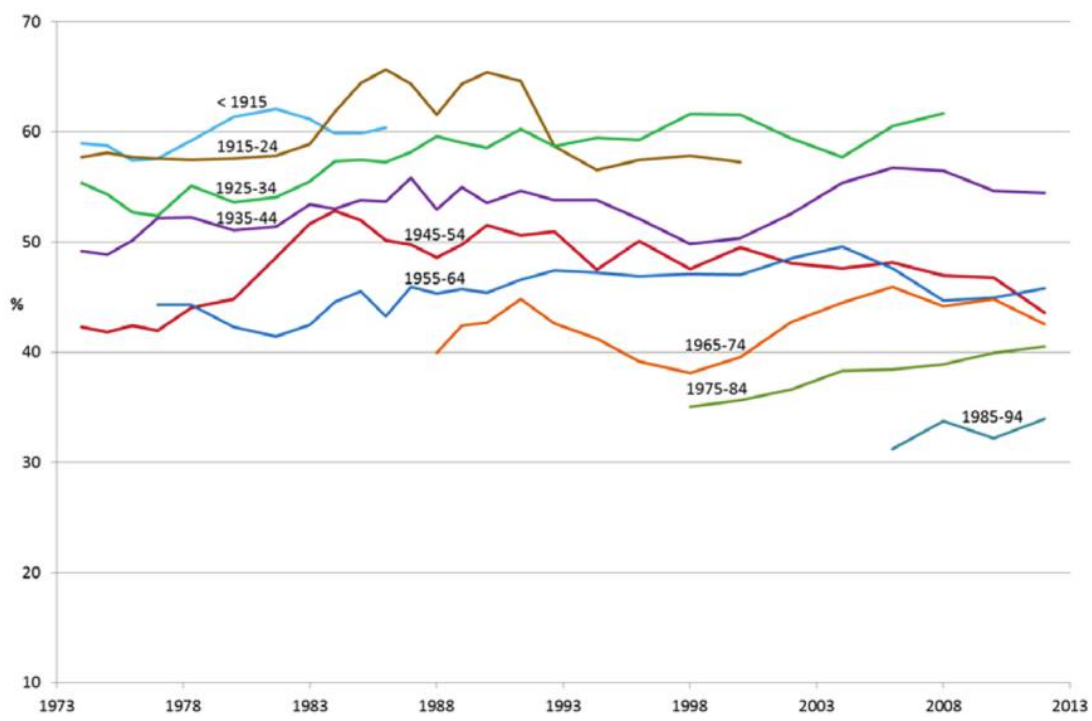

FIG. 9.-Attendance monthly or more often by decade of birth, United States, 19732014. Data are from the General Social Survey, 1974-2014. Includes respondents age 20-84 born in the United States. Three-survey moving average. To avoid overstating religious decline, the unusually religious 1972 GSS sample has been excluded.

followed by rising participation in the 1980s, after which within-cohort change is very minor.

As we did for affiliation, we perform two different decompositions: one for the full period and one just for the period since 1988. The results are similar to the previous findings. The substantial cohort replacement component in the full period suggests that aggregate attendance would have declined by 14.7 percentage points had cohort replacement not been partially offset by positive within-cohort change. Since 1988, the cohort replacement component $(-9.1)$ is nearly identical to the aggregate change, suggesting that cohort replacement accounts for virtually all attendance decline since $1988 .^{14}$

\section{Belief}

The generational nature of changing belief in God is also apparent in the United States, where the following question has been included on the GSS since 1988:

\footnotetext{
${ }^{14}$ Firebaugh and Harley (1991) used linear decomposition on a much shorter period (1972-89) to investigate attendance trends. Although their analysis was based on individual-level data and a multicategory dependent variable, our conclusions differ not because of any disagreements over the evidence but simply because they studied a much shorter period, alternative interpretations of the APC pattern are always available, and
} 


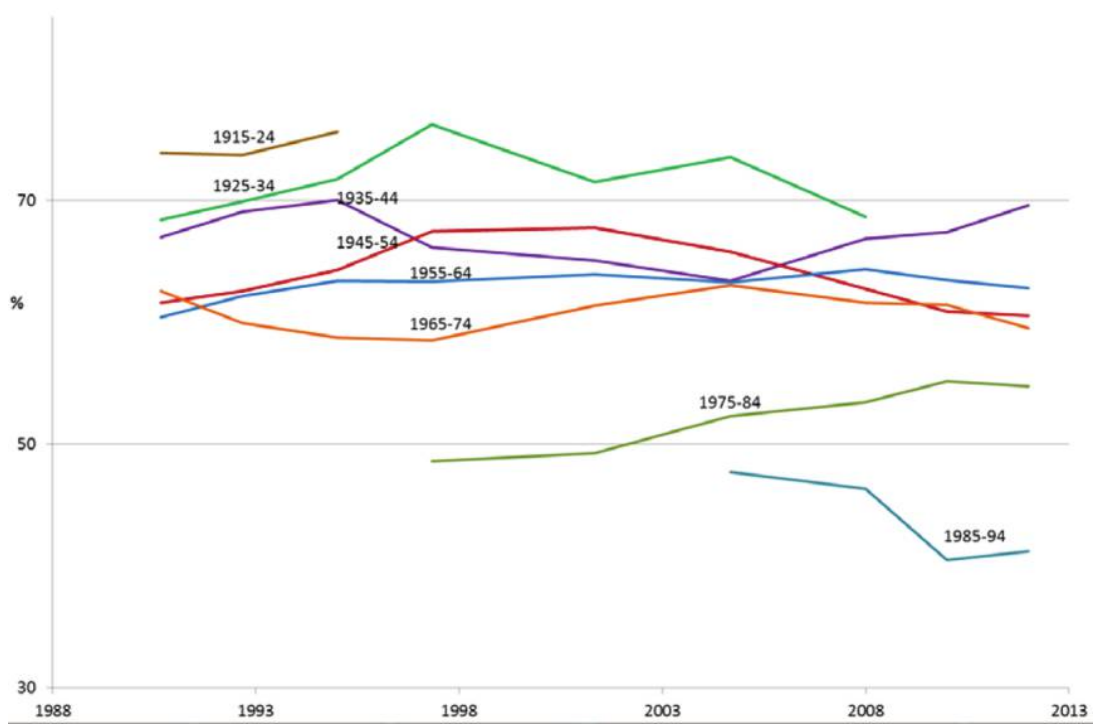

FIG. 10.-Knows God exists by decade of birth, United States, 1988-2014. Data are from the General Social Survey, 1988-2014. Includes respondents age 20-84 born in the United States. Three-survey moving average.

Please indicate which statement below comes closest to expressing what you believe about God:

- I don't believe in God;

- I don't know whether there is a God, and I don't believe there is a way to find out;

- I don't believe in a personal God, but I do believe in a Higher Power of some kind;

- I find myself believing in God some of the time, but not at others;

- While I have doubts, I feel that I do believe in God;

- I know God really exists and have no doubts about it.

As figure 10 shows, until recent years a majority of respondents in every birth cohort selected the last, most confidently theistic option. There is considerable statistical noise in the data, but after a quarter of a century a pattern is coming into view. The proportion of unequivocal believers is falling, and the most recent cohorts seem to be opening up a gap with earlier ones. In 2014 , only $45 \%$ of young adults age 18-30 had no doubts about God's existence, compared with $68 \%$ of people age 65 and over. The trend lines show steady generational drift away from unwavering belief, and there are few signs of change with age or over time. The cohort replacement compo-

their age-effects-only interpretation seemed plausible at the time. With the benefit of an additional quarter of a century of data, however, an age-effects-only model is no longer sustainable. 
nent in table $1(-7.9)$ is more than sufficient to account for the aggregate change. The overall level of belief in God is being eroded as people born early in the 20th century are replaced in the population by members of subsequent generations with weaker religious convictions.

\section{Upbringing}

Of GSS respondents born before 1925, nearly all (98\%) claim to have been raised in a religion; only $87 \%$ of those born since 1985 say the same. And whereas in earlier decades people who grew up without a religion tended to acquire one in later life (often at marriage), individuals who were not raised in a religion increasingly remain unaffiliated.

The questions on religious socialization included in the GSS in 1991, 1998, and 2008 also reveal striking generational differences, but the small sample sizes limit the depth of our cohort analysis for these items. To shift the focus from affiliation to attendance, $72 \%$ of GSS respondents born before 1935 claim to have attended religious services "nearly every week" or more often when age 11 or 12; for respondents born since 1965, the figure is $58 \%$. At least part of the explanation is unsurprising: parents are less likely to be churchgoers than in the past. Among people born before 1935, 61\% said that when they were children their mothers attended nearly every week or more often. The figure is $56 \%$ for respondents born since 1965 . Fathers are not such frequent attenders; the corresponding values are $48 \%$ and $41 \%$ for the older and younger generations, respectively. Americans are increasingly less likely to grow up in households with religiously active parents and, overall, are less likely to be religiously socialized as children. This decline in religious socialization is surely a key part of the explanation of cohort differences in adult religiosity. Cohort-based decline tends to be self-reinforcing, which has important implications for the future of religious involvement.

\section{Immigration and subpopulations}

Our main aim has been to show that cohort replacement is eroding religious involvement in a number of countries, including the United States. The relationship between immigration and religion is not directly relevant to this claim because cohort replacement could be exerting downward pressure on religiosity even if the religious population is replenished through immigration. Even if immigration to the United States was sufficiently high and immigrants were sufficiently religious to prevent drops in aggregate religiosity, that would not make the United States a secularization counterexample. To use a physical analogy, the secularization thesis is that the warm bath of religiosity gradually cools in the cold climate of modern life. 
That thesis does not become untrue because the bath can be topped up with hot water.

In fact, however, including immigrants in the analysis makes no substantive difference to U.S. trends. Recent immigrants to the United States are only slightly more religious than the native born. Using the entire GSS span, the largest difference between immigrants and the native born on any of our indicators is only 3 percentage points: $62 \%$ of the native born say that they know God exists versus $65 \%$ for immigrants. ${ }^{15}$ And there is no difference at all between immigrants and the native born in the proportion who say they have no religion. The differences are larger if we focus just on the youngest cohorts or on the most recent years but not large enough to change the main story. The aggregate trends in U.S. religiosity that we described earlier include immigrants, implying that recent immigration has not altered the slow decline in religiosity, and it does not appear likely to do so in the near future. And none of the graphs we have presented look different if we include immigrants in the analysis. Immigrants and immigration have shaped and continue to shape American religion and society in important ways, but new arrivals are too small a share of the population and are not sufficiently religious to alter the trends and cohort patterns we have examined here.

One might also wonder whether generational decline in religious involvement is largely confined to particular subsets of the population, such as white men. It is not. For example, using the full span of the GSS, $83 \%$ of black Americans born before 1925, but only $40 \%$ of those born since 1985, were or are strongly affiliated. More than three-quarters $(76 \%)$ of that older black cohort said that they attend at least monthly; less than half (48\%) of the younger cohort say the same. Graphs like those we have presented look basically the same when limited to African-Americans. Women tend to be more religious than men, but again the pattern of cohort decline is the same for both. There are, of course, many kinds of subgroups for which one might examine cohort patterns in religiosity, and there may well be subgroup differences - for example, between regions, religious groups, or socioeconomic categories - to be discovered. We hope that future research will pursue this agenda. ${ }^{16}$ For now, though, the key point is that any subgroup

${ }^{15}$ The GSS is more suitable for comparisons of the native and foreign-born than many realize. In 2012, only $1 \%$ of the initial GSS sample was excluded because of a language barrier, i.e., because no adult in the sampled household was able to complete the interview in English or Spanish (Tom Smith, personal communication), and the foreign-born proportion in the GSS is nearly identical to census estimates. The 2010 American Community Survey puts the foreign-born population at 13\%; the GSS puts it at $13.2 \%$ in 2010, $14.7 \%$ in 2012 , and $15.8 \%$ in 2014.

${ }^{16}$ King-Hele (2010) and Smith et al. (2014, chap. 2) examine cohort patterns within religious subgroups. 
differences that might exist are not directly relevant to our primary claim that, overall, cohort replacement is pushing religiosity down in the United States. The aggregate cohort differences make clear that, whatever subgroup differences may or may not exist, they net out to a national pattern of substantial cohort change in religiosity.

\section{CONCLUSION}

We have established three central empirical claims. First, religiosity has been declining in the United States for decades, albeit slowly and from high levels. Second, religious commitment is weakening from one generation to the next in the countries with which the United States has most in common, and generational differences are the main driver of the aggregate decline. Third, the same pattern of cohort replacement is behind American religious decline. This decline seems to have begun with cohorts born early in the 20th century. At least since then, strong religious affiliation, church attendance, and firm belief in God have all fallen from one birth cohort to the next. None of these declines is happening fast, and levels of religious involvement in the United States remain high by world standards. But the signs of both aggregate decline and generational differences are now unmistakable.

Our primary contribution, however, is theoretical. Most research that compares American religion with religion elsewhere emphasizes the high levels of participation in the United States and treats those high levels as strong evidence that the United States is a decisive counterexample to the secularization thesis. We have focused on trends, and we have maintained that both the now-clear fact of religious decline in the United States and the cohort-driven nature of that decline show that the United States should no longer be considered a counterexample. On the contrary, religious change in the United States is very similar to religious change elsewhere: there is longterm decline produced mainly by generational replacement. This process operates slowly, and it can be counteracted in the short term by short-lived revivals, but it is very difficult to reverse. Children are raised by parents who are less religious than their parents were, and the culture is gradually reshaped with the passing of each successive generation.

We offer three concluding remarks. First, an obvious agenda for future research is to try to understand better the causal mechanisms that lie behind these cohort differences. What social and cultural changes make each generation slightly less religious than the previous one? What is the relative importance of changes in geographical mobility, family structure, education, technology, economic conditions, and other factors? Our aim has been to highlight the role of generational replacement in religious decline in the 
West. We have not tried to identify all the causal forces at work, but we hope future research will make progress on this agenda.

Second, by emphasizing an important way in which American religion is similar to religion elsewhere in the West, we do not mean to imply that there are no important differences between religion in the United States and religion elsewhere. There certainly are ways in which American religion is unique, and there remains much to explain about how it is different from religion elsewhere in the modern world. Nor do we mean to imply that there are no important differences among other Western nations in religious trends. Every country's experience of secularization is unique when it comes to specifics like the onset of decline, the rate of decline, and contingencies that may accelerate or offset cohort-driven decline in a particular time and place. Some scholars have stressed the variety of paths by which societies have secularized or the variety of forms that secularity can take (Martin 2005; Wohlrab-Sahr and Burchardt 2012). At the same time, however, Voas (2009) showed that, although historical, political, cultural, social, and economic differences among the dozens of European countries produced substantial variation in the onset of secularization across the continent, once it begins the pattern of change looks very similar in all of them. The differences are a matter of history and culture, and explaining them always requires a combination of the general and the particular. But these differences should not obscure the reality that there is a general pattern of religious decline that characterizes the West, including the United States.

There are particularities to explain, but the appropriate comparative question changes. We should ask, "Why did secularization start in the United States when it did, and why is it proceeding at the pace that it is, with the fits and starts specific to the United States?" This is very different from the traditional question, "Why is secularization not occurring in the United States?" It may well be that some of the same explanatory factors invoked in answers to the traditional question - such as church-state separation or immigration history - help to explain why religious decline started later and is occurring more slowly in the United States than in some other places, even while, over the long run, religious involvement is being undermined by the same forces that have operated in the rest of the industrial and postindustrial world. The difference between these two questions is important, even if the answer to the newer question draws heavily on attempts to answer the older one. ${ }^{17}$

${ }^{17}$ Bruce makes a similar point when he suggests that, if the religious trajectories of the United States and Europe are not qualitatively different, then "we need only to explain why religion in America has been slower than its European counterparts to show signs of secularization" (2011, p. 176). We are not so sure, however, that the pace of secular- 
The larger theoretical point here is that connecting the timing and speed of U.S secularization to features peculiar to the United States does not make the country a counterexample to the secularization thesis any more than explaining the timing and speed of secularization in, say, France or Germany by reference to their unique history and culture makes those countries counterexamples to a more general pattern. Country-specific particularities certainly make it more difficult, perhaps impossible, to confidently forecast future levels of religiosity in the United States or elsewhere, but we are trying to establish a social regularity, not predict the future. Recognizing that the United States is not a counterexample clarifies the nature of U.S. religious exceptionalism and helps us to approach American-European religious differences in more constructive ways. ${ }^{18}$

In all comparative work there is a tension between highlighting similarities and differences. Each of the countries we have examined is distinctive. Religious affiliation is somewhat lower and declining more rapidly in Great Britain and New Zealand than in Canada and Australia. Withincohort change is nonexistent in Britain, modest in Canada and Australia, and more substantial in New Zealand. The American pattern is not identical to those seen elsewhere, and the trends in other countries are not identical to one another. Our claim is simply that recognizing major points of cross-national similarity in religious change is as important as explaining the differences.

Our third and final concluding remark returns to the larger debate about secularization and the special role that the United States has played in that debate. In recent years, accepting the United States as a decisive counterexample to the secularization thesis has led some scholars to suggest that the modernization-secularization connection is a peculiar historically contingent fact about Europe rather than a more widely applicable sociological process. If modernization in the United States has not led to secularization, this argument goes, there is little reason to think that modernization will lead to secularization elsewhere in the world, outside of Europe, Canada, and Australia. Greeley put it this way: "Why, it is often asked, . . . is the United States so different from Europe, where 'secularization' is so much further advanced? I suggest that if Europe is indeed secularized, then a

ization in the United States, at least since 1988, is slower than it is everywhere else. Moreover, comparing the rate of change across countries is complicated by Voas's (2009) finding that the pace of secularization is related to how recently it began. In any event, systematically comparing rates of religious decline across countries is beyond the scope of this article.

${ }^{18}$ It is worth noting that our position is in line with recent research on cross-national differences in religiosity in which, by contrast with the Wald and Calhoun-Brown (2011) graph we described in the introduction, the United States is not any sort of outlier. See, e.g., Ruiter and van Tubergen (2009) and Norris (2013). 
consideration of religious practice in the rest of the world indicates that Europe, not the United States, is unique" (1989, p. 117). For Berger et al., "the crucial theoretical issue . . can be summarized as follows: is Europe secular because it is modern, or is Europe secular because is it European?" (2008, p. 6). And Martin made the point in a particularly expansive way: "The much debated question as to whether Europe or North America is an exception to the proper course of history has been transferred to the whole world. To some degree the future of Christianity depends on the answer to that question" (2011, p. 66).

Whether the United States is a counterexample thus opens into the larger question whether modernity, sooner or later, will bring secularization. This is of course a classic question in sociology. For a long time the majority of social scientists answered affirmatively, but the critics of secularization turned the tide so effectively that today the weight of scholarly opinion is on the other side. America's accepted status as a counterexample did much to shift opinion in that direction. We are not prepared to say that removing that status should by itself reinstate the old idea that modernity everywhere will bring secularization eventually. We are prepared to say, however, that since it is no longer clear that the United States is on a qualitatively different religious trajectory than Europe, it is too soon to assert that the secularization thesis does not apply outside of Europe, Canada, and Australia. It now seems that the classic question - does modernization undermine religion? - has been prematurely answered, "not in general." That answer should be reconsidered in light of the evidence we have presented here.

Our goal has been to establish that the United States should no longer be considered a counterexample to the secularization thesis. We do not claim that altering the theoretical status of American religion in this way proves that the secularization thesis is correct. It may be that the full range of relevant evidence justifies rejecting the thesis, regardless of our findings. Although we do not think that is the case, our goal has not been to defend the secularization thesis in its entirety but to challenge the essentially unquestioned status of the United States as decisive evidence against it. Undermining the America-as-counterexample claim will not settle the secularization debate, but it should alter the ground on which it is conducted.

\section{APPENDIX}

\section{Linear Decomposition}

The numbers in table 1 are based on Firebaugh's technique for decomposing aggregate change into within- and between-cohort components (Firebaugh and Davis 1988; Firebaugh 1989, 1997). The starting point is a straightfor- 
ward linear regression of some measure of religious participation $(y)$ on survey year and birth year:

$$
y_{i j}=\alpha+\beta_{1} \text { survey year }_{i}+\beta_{2} \text { birth year }_{j}+\varepsilon_{i j} \text {. }
$$

Although the method was devised for individual-level data, it also is suitable for aggregate data, where the $y_{i j}$ are mean values for the survey year/ birth year combination. We simply weight the data according to the percentage of respondents within a given survey year who were born in each year. This strategy has the advantage that we can allow for changes in the sample size over time; in aggregate, each calendar year receives equal weight. By halving the weights for GSS years up to 1991, we also easily adjust for the overrepresentation of years during the period when the GSS was conducted every year instead of every other year. In doing so we follow the recommendation of Firebaugh and Davis (1988, p. 258).

Having performed this weighted least squares regression, we then multiply the survey year coefficient by the length of the time span between the first and last survey to estimate the impact of intracohort change over the period of observation. Similarly, we multiply the birth year coefficient by the difference between the mean birth years at the beginning and end of the period to estimate the effect of cohort replacement. The sum of these two estimates should be close to the actual change over the period if there are not large nonlinearities or interactions in the data.

For Australia and New Zealand, the actual values come from censuses, and so no smoothing is necessary. For Great Britain, Canada, and the United States, the religious indicators come from surveys and are subject to sampling error. We average the indicator values for the first and last two years in each series to obtain more reliable measures of change over the full period. These measures are then adjusted to apply to the full period, rather than to the slightly shorter span between the averaged years (and hence the figure in table 1 col. 5 is not simply the difference between those in cols. 3 and 4). For example, if the series covers 1980, 1982, . . 2010, 2012, the difference between the averaged first and last two values will reflect change over the 30-year period between 1981 and 2011; multiplying that difference by $32 / 30$ gives us a smoothed estimate of change over the full period from 1980 to 2012 .

As can be seen in table 1, our models all fit the data well; they produce aggregate change estimates that are close to the observed change. The discrepancy is typically no more than a percentage point.

If cohort replacement and intracohort change push in the same direction, then the cohort replacement effect can be divided by the sum of the inter- and intracohort effects to yield an estimate of the proportion of total aggregate change attributable to cohort replacement. But this calculation 
is not sensible when, as in some of our data, cohort replacement and intracohort change work in opposite directions. In our data, cohort replacement always pushes aggregate religiosity down, but in some cases intracohort change pushes it up, although never by enough to offset the force of cohort replacement. In these instances, the cohort replacement component can be interpreted as an estimate of how much aggregate religiosity would have declined because of cohort replacement were it not for intracohort change in the other direction.

The graphical and linear decomposition methods provide distinct and complementary descriptions. In the graphical approach, multiple birth years (usually 10) are collapsed into a single cohort, and the three-survey moving averages provide a degree of smoothing within each cohort, but otherwise the points plotted show the full complexity of change between and within cohorts. By contrast, the statistical decomposition is based on raw values for each individual year of birth and survey year, from which the regression produces smooth trends.

\section{REFERENCES}

Baker, Joseph O'Brian, and Buster Smith. 2009. "None Too Simple: Examining Issues of Religious Nonbelief and Nonbelonging in the United States." Journal for the Scientific Studv of Religion 48 (4): 719-33.

Bell, Andrew, and Kelvyn Jones. 2014. "Another 'Futile Quest'? A Simulation Study of Yang and Land's Hierarchical Age-Period-Cohort Model." Demographic Research 30: 333-60.

Berger, Peter, Grace Davie, and Effie Fokas. 2008. Religious America, Secular Europe? $A$ Theme and Variations. Burlington, Vt.: Ashgate.

Bongaarts, John, and Tomáš Sobotka. 2012. "A Demographic Explanation for the Recent Rise in European Fertility." Population and Development Review 38 (1): 83-120.

Brenner, Philip S. 2011. "Exceptional Behavior or Exceptional Identity? Overreporting of Church Attendance in the U.S." Public Opinion Quarterly 75 (1): 19-41.

. 2012. "Identity as a Determinant of the Overreporting of Church Attendance in Canada." Journal for the Scientific Studv of Religion 51 (2): 377-85.

Bruce, Steve. 2011. Secularization: In Defence of an Unfashionable Theorv. Oxford: Oxford University Press.

Chaves, Mark. 1989. "Secularization and Religious Revival: Evidence from U.S. Church Attendance Rates, 1972-1986." Journal for the Scientific Study of Religion 28 (4): 464-77.

1991. "Family Structure and Protestant Church Attendance: The Sociological Basis of Cohort and Age Effects." Journal for the Scientific Studv of Religion 30 (4): 501-14.

- 2011. American Religion: Contemporarv Trends. Princeton, N.J.: Princeton University Press.

Crockett, Alasdair, and David Voas. 2006. "Generations of Decline: Religious Change in Twentieth-Century Britain." Journal for the Scientific Studv of Religion 45 (4): 567-84.

De Graaf, Nan Dirk. 2013. "Secularization: Theoretical Controversies Generating Empirical Research.” Pp. 321-54 in Handbook of Rational Choice Social Research, edited by Rafael Wittek, Tom A. B. Snijders, and Victor Nee. Stanford, Calif.: Stanford University Press. 


\section{American Journal of Sociology}

Firebaugh, Glenn. 1989. "Methods for Estimating Cohort Replacement Effects.” Sociological Methodology 19:243-62.

. 1997. Analyzing Repeated Surveys. Thousand Oaks, Calif.: Sage.

Firebaugh, Glenn, and Kenneth E. Davis. 1988. "Trends in Antiblack Prejudice, 19721984: Region and Cohort Effects.” American Journal of Sociology 94 (2): 251-72.

Firebaugh, Glenn, and Brian Harley. 1991. "Trends in U.S. Church Attendance: Secularization and Revival, or Merely Lifecycle Effects?" Journal for the Scientific Studv of Religion 30 (4): 487-500.

Fischer, Claude S., and Michael Hout. 2006. Century of Difference: How Americans Changed in the Last One Hundred Years. New York: Russell Sage.

Glenn, Norval D. 2005. Cohort Analysis, 2d ed. Thousand Oaks, Calif.: Sage.

Gorski, Philip S., and Ates Altinordu. 2008. "After Secularization?" Annual Review of Sociology 34:55-85.

Grant, J. Tobin. 2008. "Measuring Aggregate Religiosity in the United States, 1952-2005." Sociological Spectrum 28 (5): 460-76.

Greeley, Andrew M. 1989. Religious Change in America. Cambridge, Mass.: Harvard University Press.

Hadaway, C. Kirk, Penny Long Marler, and Mark Chaves. 1993. "What the Polls Don’t Show: A Closer Look at U.S. Church Attendance.” American Sociological Review 58 (6): 741-52.

Hofferth, Sandra L., and John F. Sandberg. 2001. "Changes in American Children's Time, 1981-1997." Pp. 193-229 in Children at the Millennium: Where Have We Come From, Where Are We Going? Advances in Life Course Research, edited by Timothy Owens and Sandra Hofferth. New York: Elsevier Science.

Hout, Michael, and Claude S. Fischer. 2014. "Explaining Why More Americans Have No Religious Preference: Political Backlash and Generational Succession, 19872012." Sociological Science 1:423-47.

Hout, Michael, Claude S. Fischer, and Mark Chaves. 2013. "More Americans Have No Religious Preference: Key Findings from the 2012 General Social Survey.” Working paper. University of California, Berkeley, Institute for the Study of Societal Issues.

Hout, Michael, and Andrew M. Greeley. 1987. "The Center Doesn't Hold: Church Attendance in the United States, 1940-1984." American Sociological Review 52 (3): $325-45$.

1990. "The Cohort Doesn't Hold: Comment on Chaves (1989)." Journal for the Scientific Studv of Religion 29 (4): 519-24.

Karlamangla, Arun, Kefei Zhou, David Reuben, Gail Greendale, and Alison Moore. 2006. "Longitudinal Trajectories of Heavy Drinking in Adults in the United States of America." Addiction 101 (1): 91-99.

King-Hele, Sarah. 2010. "The Dynamics of Religious Change: A Comparative Study of Five Western Countries.” Ph.D. dissertation. University of Manchester.

Kosmin, Barry, and Ariela Keysar. 2009. "American Nones: The Profile of the No Religion Population; A Report Based on the American Religious Identification Survey, 2008." Program on Public Values, Trinity College, Hartford, Conn.

Kraaykamp, Gerbert. 2002. "Trends and Countertrends in Sexual Permissiveness: Three Decades of Attitude Change in the Netherlands, 1965-1995." Journal of Marriage and Family 64 (1): 225-39.

Lipset, Seymour Martin. 1959. "Some Social Requisites of Democracy: Economic Development and Political Legitimacy." American Political Science Review 53 (1): 69-105.

Luckmann, Thomas. 1967. The Invisible Religion. New York: Macmillan.

Luo, Liying. 2013. "Assessing Validity and Application Scope of the Intrinsic Estimator Approach to the Age-Period-Cohort Problem." Demographv 50 (6): 1945-67.

Luo, Liying, and James Hodges. Forthcoming. "Block Constraints in Age-PeriodCohort Models with Unequal-Width Intervals." Sociological Methods and Research. doi:10.1177/0049124115585359. 
Martin, David. 2005. On Secularization: Towards a Revised General Theory. Aldershot: Ashgate.

- 2011. The Future of Christianity: Reflections on Violence and Democracy, Religion and Secularisation. Aldershot: Ashgate.

Miller, Alan S., and Takashi Nakamura. 1996. "On the Stability of Church Attendance Patterns during a Time of Demographic Change, 1965-1988." Journal for the Scientific Studv of Religion 35 (3): 275-84.

Newport, Frank. 2012. God Is Alive and Well: The Future of Religion in America. New York: Gallup.

Norris, Pippa. 2013. "Why Insecurity Drives Religiosity: New Evidence.” Paper presented at the annual meetings of the Society for the Scientific Study of Religion, Boston, November 9.

Norris, Pippa, and Ronald Inglehart. 2004. Sacred and Secular: Religion and Politics Worldwide. New York: Cambridge University Press.

Pelzer, Ben, Manfred te Grotenhuis, Rob Eisinga, and Alexander W. Schmidt-Catran. 2015. "The Non-uniqueness Property of the Intrinsic Estimator in APC Models." Demographv 52 (1): 315-27.

Pew Research Center. 2012. "Nones” on the Rise: One-in-Five Adults Have No Religious Affiliation. Washington, D.C.: Pew Research Center.

Ploch, Donald R., and Donald W. Hastings. 1994. "Graphic Representations of Church Attendance Using General Social Survey Data." Journal for the Scientific Studv of Religion 33 (1): 16-33.

Presser, Stanley, and Mark Chaves. 2007. "Is Religious Service Attendance Declining?" Journal for the Scientific Study of Religion 46 (3): 417-23.

Presser, Stanley, and Linda Stinson. 1998. "Data Collection Mode and Social Desirability Bias in Self-Reported Religious Attendance." American Sociological Review 63 (1): $137-45$.

Putnam, Robert D., and David E. Campbell. 2010. American Grace: How Religion Divides and Unites Us. New York: Simon \& Schuster.

Robinson, Robert V., and Elton F. Jackson. 2001. "Is Trust in Others Declining in America? An Age-Period-Cohort Analysis." Social Science Research 30 (1): 117-45.

Ruiter, Stijn, and Frank van Tubergen. 2009. "Religious Attendance in Cross-National Perspective: A Multilevel Analysis of 60 Countries.” American Journal of Sociology 115 (3): 863-95.

Ryder, Norman. 1965. "The Cohort as a Concept in the Study of Social Change." American Sociological Review 30 (6): 843-61.

Sasaki, Masamichi, and Tatsuzo Suzuki. 1987. "Changes in Religious Commitment in the United States, Holland, and Japan." American Journal of Sociology 92 (5): 105576.

Schwadel, Philip. 2010a. "Age, Period, and Cohort Effects on U.S. Religious Service Attendance: The Declining Impact of Sex, Southern Residence, and Catholic Affiliation." Sociology of Religion 71 (1): 2-24.

. 2010b. "Period and Cohort Effects on Religious Nonaffiliation and Religious Disaffiliation: A Research Note." Journal for the Scientific Studv of Religion 49 (2): 311-19.

2011. "Age, Period, and Cohort Effects on Religious Activities and Beliefs." Social Science Research 40 (1): 181-92.

. 2013. "Changes in Americans' Strength of Religious Affiliation, 1974-2010." Sociology of Religion 74 (1): 107-28.

Smith, Christian, Kyle Longest, Jonathan Hill, and Kari Christofferson. 2014. Young Catholic America: Emerging Adults In, Out of, and Gone from the Church. New York: Oxford University Press.

Smith, Tom W. 2009. "Religious Change around the World." General Social Survey Cross-National report no. 30. NORC, Chicago. 


\section{American Journal of Sociology}

Smith, Tom W., Peter V. Marsden, and Michael Hout. 2015. "General Social Surveys, 1972-2014." Machine readable data file. NORC, Chicago.

Torpey, John. 2010. "American Exceptionalism?” Pp. 141-59 in The New Blackwell Companion to the Sociology of Religion, edited by Brian S. Turner. Chichester: Blackwell.

U.S. Bureau of the Census. 1958. Religion Reported by the Civilian Population of the United States: March 1957. Current Population Reports: Population Characteristics series P-20, no. 79. Washington, D.C.: Government Printing Office.

Van Ingen, Erik. 2008. "Social Participation Revisited: Disentangling and Explaining Period, Life-Cycle and Cohort Effects." Acta Sociologica 50 (2): 103-21.

Veevers, Jean E., and Ellen M. Gee. 1988. "Religiously Unaffiliated Canadians: Demographic and Social Correlates of Secularization." Pp. 17-20 in The Review of Demography and Its Implications for Economic and Social Policy: Update Number Five. Ottawa: Health \& Welfare Canada.

Vezzoni, Cristiano, and Ferruccio Biolcati-Rinaldi. 2015. "Church Attendance and Religious Change in Italy, 1968-2010: A Multilevel Analysis of Pooled Datasets." Journal for the Scientific Studv of Religion 54 (1): 100-118.

Voas, David. 2009. "The Rise and Fall of Fuzzy Fidelity in Europe." European Sociological Review 25 (2): 155-68.

Voas, David, and Alasdair Crockett. 2005. "Religion in Britain: Neither Believing nor Belonging." Sociology 39 (1): 11-28.

Voas, David, and Stefanie Doebler. 2011. "Secularization in Europe: Religious Change between and within Birth Cohorts." Journal of Religion and Society in Central and Eastern Europe 4 (1): 39-62.

Wald, Kenneth D., and Allison Calhoun-Brown. 2011. Religion and Politics in the United States, 6th ed. New York: Rowman \& Littlefield.

Wohlrab-Sahr, Monika, and Marian Burchardt. 2012. "Multiple Secularities: Toward a Cultural Sociology of Secular Modernities.” Comparative Sociology 11 (6): 875-909.

Wolf, Christof. 2008. "How Secularized Is Germany? Cohort and Comparative Perspectives." Social Compass 55 (2): 111-26.

Wuthnow, Robert. 2007. After the Baby Boomers: How Twenty-and Thirty-Somethings Are Shaping the Future of American Religion. Princeton, N.J.: Princeton University Press.

Yang, Yang. 2008. "Social Inequalities in Happiness in the United States, 1972 to 2004: An Age-Period-Cohort Analysis." American Sociological Review 73 (2): 204-26.

Yang, Yang, Wenjiang Fu, and Kenneth C. Land. 2004. "A Methodological Comparison of Age-Period-Cohort Models: The Intrinsic Estimator and Conventional Generalized Linear Models." Sociological Methodology 34:75-110.

Yang, Yang, and Kenneth C. Land. 2006. "A Mixed Models Approach to the AgePeriod-Cohort Analysis of Repeated Cross-Section Surveys, with an Application to Data on Trends in Verbal Test Scores." Sociological Methodology 36:75-97.

- 2013a. Age-Period-Cohort Analysis: New Models, Methods, and Empirical Applications. Boca Raton, Fla.: CRC.

_ 2013b. "Misunderstandings, Mischaracterizations, and the Problematic Choice of a Specific Instance in Which the IE Should Never Be Applied.” Demographv 50 (6): 1969-71.

Yang, Yang, Sam Schulhofer-Wohl, Wenjiang Fu, and Kenneth C. Land. 2008. "The Intrinsic Estimator for Age-Period-Cohort Analysis: What It Is and How to Use It." American Journal of Sociologv 113 (6): 1697-1736. 